\title{
GluR $\delta 2$ Assembles Four Neurexins into Trans-Synaptic Triad to Trigger Synapse Formation
}

\author{
Sung-Jin Lee, Takeshi Uemura, Tomoyuki Yoshida, and Masayoshi Mishina \\ Department of Molecular Neurobiology and Pharmacology, Graduate School of Medicine, University of Tokyo, Tokyo 113-0033, Japan
}

Elucidation of molecular mechanisms of synapse formation is a prerequisite for the understanding of neural wiring, higher brain functions, and mental disorders. The trans-synaptic interaction of postsynaptic glutamate receptor $\delta 2$ (GluR $\delta 2$ ) and presynaptic neurexins (NRXNs) through cerebellin precursor protein 1 (Cbln1) mediates synapse formation in vivo in the cerebellum. Here, we asked how the trans-synaptic triad induces synapse formation. Native GluR $\delta 2$ existed as a tetramer in the membrane, whereas the $\mathrm{N}$-terminal domain (NTD) of GluR $\delta 2$ formed a stable homodimer. When incubated with cultured mouse cerebellar granule cells (GCs), dimeric GluR $\delta 2$-NTD and Cbln1 exerted little effect on the accumulation of punctate immunostaining signals for Bassoon and vesicular glutamate transporter 1 in GC axons. However, tetramerized GluR $\delta 2$-NTD stimulated the accumulation of these presynaptic proteins in the axons. Analysis of Cbln1 mutants suggested that the binding sites of GluR $\delta 2$ and NRXN1 $\beta$ on Cbln 1 are differential. Furthermore, there was no competition in the binding to Cbln 1 between GluR $\delta 2$-NTD and the extracellular domain (ECD) of NRXN1 $\beta$. Thus, GluR $\delta 2$ and Cbln 1 interacted with each other rather independently of Cbln1-NRXN1 $\beta$ interaction and vice versa. Gel filtration and isothermal titration calorimetry analyses consistently showed that dimeric GluR $\delta 2$-NTD and hexameric Cbln1 assembled in the 1:1 ratio, whereas hexameric Cbln1 and the laminin-neurexin-sex hormone-binding globulin domain of NRXN1 $\beta$-ECD assembled in the 1:2 ratio. Thus, the synaptogenic triad is assembled from tetrameric GluR $\delta 2$, hexameric Cbln1, and monomeric NRXN in the ratio of 1:2:4. These results suggest that GluR $\delta 2$ triggers synapse formation by clustering four NRXNs through triad formation.

\section{Introduction}

Synapse formation is a key step in the development of neuronal networks. Precise synaptic connections between nerve cells in the brain provide the basis of perception, learning, memory, and cognition. Thus, elucidation of molecular mechanisms that regulate the formation and modulation of central synapses is essential for the understanding of neural wiring, brain functions, and mental disorders such as schizophrenia, autism, and mental retardation. Excitatory synapse formation in the brain requires the coordinate assembly of large numbers of protein complexes and specialized membrane domains required for synaptic transmission (Waites et al., 2005; McAllister, 2007). A number of transsynaptic cell adhesion molecules have been identified that play roles in synapse formation in vitro (Dalva et al., 2007; Südhof, 2008; Shen and Scheiffele, 2010; Williams et al., 2010; Siddiqui and Craig, 2011). The most extensively studied example is the trans-synaptic interaction between neuroligins (NLGNs) and

Received Nov. 6, 2011; revised Feb. 3, 2012; accepted Feb. 18, 2012.

Author contributions: S.-J.L. and M.M. designed research; S.-J.L., T.U., and T.Y. performed research; S.-J.L., T.U., and T.Y. analyzed data; S.-J.L. and M.M. wrote the paper.

The authors declare no competing financial interests.

This work was supported in part by research grants from the Ministry of Education, Culture, Sports, Science, and Technology of Japan. We are grateful to Dr. S. Fukai for advice on the model of Cbln1 structure, Drs. T. Shimizu and S. Tokuoka for use of the BIAcore 3000 biosensor, Dr. M. Watanabe for anti-GluR $\delta 2$ and anti-VGluT1 antibodies, A. Maeda for technical assistance, and R. Suzuki for help in preparation of this manuscript.

Correspondence should be addressed to Masayoshi Mishina, Department of Molecular Neurobiology and Pharmacology, Graduate School of Medicine, University of Tokyo, Tokyo 113-0033, Japan. E-mail: mishina@m.u-tokyo.ac.jp.

DOI:10.1523/JNEUROSCI.5584-11.2012

Copyright $\odot 2012$ the authors $\quad 0270-6474 / 12 / 324688-14 \$ 15.00 / 0$ neurexins (NRXNs). Cell culture studies indicate that postsynaptic NLGNs and presynaptic NRXNs could act bidirectionally to induce presynaptic and postsynaptic assembly, thus controlling synapse formation in vitro (Scheiffele et al., 2000; Dean et al., 2003; Graf et al., 2004). However, phenotypic analyses of NLGN1-3 triple-knock-out mice suggest that these molecules are essential for synaptic function but not for synapse formation in vivo (Varoqueaux et al., 2006; Südhof, 2008). Despite the wealth of information, there remained many questions about the mechanism of synapse formation and the precise in vivo roles of multiple trans-synaptic cell adhesion molecules in various steps of synapse formation (Waites et al., 2005; Dalva et al., 2007; McAllister, 2007; Williams et al., 2010; Siddiqui and Craig, 2011).

GluR $\delta 2$, a member of the $\delta$-type glutamate receptor (GluR), plays an essential role in vivo in cerebellar Purkinje cell (PC) synapse formation (Kashiwabuchi et al., 1995; Kurihara et al., 1997; Takeuchi et al., 2005). The cerebellum receives two excitatory afferents, the climbing fiber and the mossy fiber-parallel fiber (PF) pathway, both converging onto PCs that are the sole neurons sending outputs from the cerebellar cortex. GluR $\delta 2$ is selectively expressed in cerebellar PCs (Araki et al., 1993; Lomeli et al., 1993) and is exclusively localized at PF-PC synapses (Takayama et al., 1996; Landsend et al., 1997). In conventional and conditional GluR $\delta 2$ knock-out mice, a significant number of PC spines lack synaptic contacts with PF terminals, and some of residual PF-PC synapses show mismatching between presynaptic and postsynaptic specializations (Kashiwabuchi et al., 1995; Kurihara et al., 1997; Takeuchi et al., 2005). These studies indicate that the formation and maintenance of PF-PC synapses are 
critically dependent on GluR $\delta 2$ in vivo. Recently, we found that the trans-synaptic interaction of postsynaptic GluR $\delta 2$ and presynaptic NRXNs through cerebellin precursor protein 1 (Cbln1) mediates PF-PC synapse formation in the cerebellum (Uemura et al., 2010). Here, we show that the synaptogenic triad is assembled from tetrameric GluR $\delta 2$, hexameric Cbln1, and monomeric NRXN in the molar ratio of 1:2:4. The assembly stoichiometry of the triad provides an insight into the molecular mechanism of PF-PC synapse formation in the cerebellum.

\section{Materials and Methods}

Construction of expression vectors. The coding sequence for GluR $\alpha 1$ lacking signal sequence was cloned into the HindIII-XbaI sites of pFLAGCMV-1 (Sigma-Aldrich) to yield pFLAG-GluR $\alpha 1$. Expression vector pEB6-HA-Cbln1-CS-His was constructed from pEB6-HA-Cbln1-His (Uemura et al., 2010) by PCR-based site-directed mutagenesis. The coding sequence for His tag was added to pEB6-HA-Cbln4 (Joo et al., 2011) by PCR to yield pEB6-HA-Cbln4-His. Expression vectors for chimeras between Cbln1 and Cbln4 (SWAP55, SWAP62, SWAP103, and SWAP146) were constructed by PCR from pEB6-HA-Cbln1-His and pEB6-HA-Cbln4-His. Expression vectors for substitution mutants W136K and SWAP57-60 were constructed from pEB6-HA-Cbln1-His by PCR-based site-directed mutagenesis. Amino acid residues of mouse Cbln 1 and Cbln 4 were numbered from the first methionine (GenBank accession numbers AAI32123 and AAI32026). The expression vector for GluR $\delta 2-N T D-F c-H i s$ was constructed from pEB6-GluR $82-N T D-F c$ (Uemura and Mishina, 2008). The coding sequence for the PreScision protease cleavage site (LEVLFQGP) followed by His tag was added to pEB6-GluR $\delta 2-N T D-F c$ by PCR to yield pEB6-GluR $\delta 2-N T D-F c-H i s$. The expression vector pEB6-GluR $82-\mathrm{NTD}-\mathrm{Fc}(\mathrm{CS})$-His was constructed from pEB6-GluR $\delta 2-N T D-F c-H i s$ by PCR-based site-directed mutagenesis. The DNA fragment encoding the amino acid residues 1-292 of NRXN1 $\beta$-containing splicing segment 4 (S4) was amplified by PCR from pEB6-NRXN1 $\beta$-ECD-Fc (Uemura et al., 2010) and cloned into the NheI-XhoI sites of pAP-tag5 (GenHunter) to yield pNRXN1 $\beta$-LNS-MH. Expression vectors for Ala substitution mutants of S4 of NRXN1 $\beta$-V5 (Gly201 to Lys230) were constructed from pNRXN1 $\beta$-V5 (Uemura et al., 2010) by PCR-based site-directed mutagenesis.

Preparation of soluble recombinant proteins. Soluble recombinant proteins were prepared as described previously (Uemura et al., 2010). Culture medium was concentrated with a GE Kvick Cassette concentrator (GE Healthcare) according to the manufacturer's instructions. Histagged proteins were purified by Talon metal affinity resin (Clontech) with a standard protocol and dialyzed against HBSS (Invitrogen). NRXN $1 \beta$-ECD-Fc was purified by rProtein A-Sepharose Fast Flow (GE Healthcare), eluted with $10 \mathrm{~mm}$ glycine, $\mathrm{pH} 2.5$, and dialyzed against HBSS. Protein concentrations were estimated by Western blotting and SDS-PAGE with Coomassie staining.

Preparation of membrane proteins. Membrane proteins were prepared essentially as described previously (Penn et al., 2008). Briefly, HEK293T cells were transfected with pFLAG-GluR $\alpha 1$, pFLAG- $\delta 2$, or pcGRD2 (Matsuda and Mishina, 2000) and were incubated for $48 \mathrm{~h}$. Membrane pellets were solubilized in $20 \mathrm{~mm}$ HEPES, pH 7.4, containing $150 \mathrm{~mm}$ $\mathrm{NaCl}, 2 \mathrm{~mm}$ EDTA, 5\% glycerol, 0.6\% CHAPS, $1 \times$ protease inhibitor mixture (Roche), and $100 \mu \mathrm{g} / \mathrm{ml}$ PMSF.

Native- and blue native-PAGE. Proteins were loaded onto 5-20\% gradient polyacrylamide gels (Bio-Rad) for native-PAGE or 4-20\% gradient polyacrylamide Bis-Tris gels (Invitrogen) for blue native (BN)-PAGE. Proteins were detected by Coomassie staining or Western blotting with rabbit anti-GluR $\delta 2$ (Araki et al., 1993), mouse anti-FLAG (SigmaAldrich), mouse anti-Myc (Santa Cruz Biotechnology), mouse anti-HA (Sigma-Aldrich), mouse anti-His (Millipore), and horseradish peroxidase (HRP)-conjugated anti-human Fc (Sigma-Aldrich) antibodies.

Cell-surface binding assay and pull-down assay. Cell-surface binding assay was performed essentially as described previously (Uemura et al., 2010). HEK293T cells transfected with expression vectors for wild-type and mutant NRXN1 $\beta$-V5 were incubated with $10 \mu \mathrm{g} / \mathrm{ml} \mathrm{HA-Cbln} 1$ in HBSS containing $2 \mathrm{mM} \mathrm{CaCl}_{2}$ and $1 \mathrm{mM} \mathrm{MgCl}_{2}$ for $1 \mathrm{~h}$. After washing, cells were fixed, permeabilized, and immunostained with mouse anti-V5 (Invitrogen) and rabbit anti-HA (Santa Cruz Biotechnology) antibodies, followed by incubation with species-specific Alexa Fluor 555- and 488conjugated secondary antibodies (Invitrogen).

For the pull-down assay, soluble recombinant proteins were mixed and incubated in $\mathrm{HBSS}$ containing $2 \mathrm{mM} \mathrm{CaCl}_{2}$ and $1 \mathrm{mM} \mathrm{MgCl}_{2}$ for $3 \mathrm{~h}$ or overnight at $4^{\circ} \mathrm{C}$, followed by incubation with rProtein A-Sepharose Fast Flow or Talon metal affinity resin for $1 \mathrm{~h}$ at $4^{\circ} \mathrm{C}$. Subsequently, suspensions were washed five times with $\mathrm{HBSS}$ containing $2 \mathrm{~mm} \mathrm{CaCl}_{2}$ and $1 \mathrm{mM} \mathrm{MgCl}_{2}$. Bound proteins were eluted by boiling in SDS sample buffer, separated by $5-20 \%$ gradient SDS-PAGE gel, and analyzed by Western blotting with mouse anti-HA, mouse anti-Myc, HRP-conjugated anti-human Fc, and HRP-conjugated anti-His (Santa Cruz Biotechnology) antibodies as described previously (Uemura et al., 2004).

Gel-filtration chromatography. Gel-filtration chromatography was performed by a fast protein liquid chromatography (FPLC) using a Superdex 200 pg (HiLoad 16/60) column (GE Healthcare) in HBSS containing $2 \mathrm{mM} \mathrm{CaCl}_{2}$ and $1 \mathrm{~mm} \mathrm{MgCl}_{2}$. Thyroglobulin, apoferritin, $\beta$-amylase, bovine serum albumin (Sigma-Aldrich), and IgG (Santa Cruz Biotechnology) were used for molecular weight (MW) standards. Purified recombinant proteins or their mixtures were injected onto the column at a volume of $1 \mathrm{ml}$. Dimeric GluR $\delta 2-\mathrm{NTD}-\mathrm{Fc}-\mathrm{His}(1 \mathrm{nmol})$ and hexameric HA-Cbln1-His ( $1 \mathrm{nmol}$ ) or monomeric NRXN1 $\beta$-LNS-MH (1-3 nmol) and HA-Cbln-His (1 nmol) were mixed and incubated overnight at $4^{\circ} \mathrm{C}$ before loading onto the column. Before loading the mixture

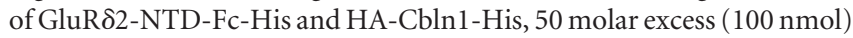
of 3,3'-dithiobis(sulfosuccinimidylpropionate) (DTSSP) was treated for $30 \mathrm{~min}$ at room temperature. The absorbance at $280 \mathrm{~nm}$ was monitored, and the $2 \mathrm{ml}$ fractions of all elutes were collected and analyzed by PAGE and immunoblotting.

Isothermal titration calorimetry assay. Isothermal titration calorimetry (ITC) was performed at $37^{\circ} \mathrm{C}$ in a MicroCal ITC-200 unit (GE Healthcare). GluR $\delta 2-N T D-F c-H i s, H A-C b l n 1-H i s$, and NRXN1 $\beta$-ECD-MH were dialyzed against $\mathrm{HBSS}$ containing $2 \mathrm{mM} \mathrm{CaCl}_{2}$ and $1 \mathrm{mM} \mathrm{MgCl}_{2}$, and dialysis buffer was used for the test. The concentrations of GluR $\delta 2-N T D-$ Fc-His and NRXN1 $\beta$-LNS-MH in the cell were 3.6 and $5.3 \mu \mathrm{M}$, respectively, and the concentration of HA-Cbln1-His in the syringe was 32.9 $\mu \mathrm{M}$. Aliquots $(3.8 \mu \mathrm{l})$ were injected, and the syringe was stirred at 1000 $\mathrm{rpm}$ while measuring heat of binding at $37^{\circ} \mathrm{C}$. After subtraction of the heats of dilution, the net enthalpy data were analyzed with a single binding model using the Origin software package.

Surface plasmon resonance binding assay. Surface plasmon resonance (SPR) binding assays were conducted on a BIAcore 3000 biosensor equipped with a sensor chip CM5 (GE Healthcare) as described previously (Uemura et al., 2010). GluR $\delta 2-N T D-F c$ and NRXN1 $\beta$-ECD-Fc were captured in flow cell 2 or 4 , and untreated flow cell 1 or 3 served as a reference. Purified Cbln proteins at the concentration of 125 or $250 \mathrm{nM}$ in the running buffer were injected in the sensor chips. Buffer blanks were injected throughout the experiment for double referencing.

Animals. Mice were fed ad libitum with standard laboratory chow and water in standard animal cages under a $12 \mathrm{~h}$ light/dark cycle. Mice of either sex were used for the experiments. All animal procedures were approved by the Animal Care and Use Committee of the Graduate School of Medicine, University of Tokyo (Approval 1721T062).

Neuronal cultures and immunostaining. Cell cultures were performed essentially as described previously (Uemura and Mishina, 2008). Briefly, primary cultures of cerebellar granule cells (GCs) were prepared from neonatal ICR mice or Cbln1 knock-out mice (Uemura et al., 2010) at postnatal day 7 and were placed on coverslips coated with poly-L-lysine $(30 \mu \mathrm{g} / \mathrm{ml})$ and mouse laminin $(10 \mu \mathrm{g} / \mathrm{ml})$ at the density of $1 \times 10^{5}$ cells $/ \mathrm{cm}^{2}$. GCs were cultured in Neurobasal A (Invitrogen) supplemented with 2\% B-27 supplement (Invitrogen), 5\% fetal calf serum (FCS), $100 \mathrm{U} / \mathrm{ml}$ penicillin, $100 \mu \mathrm{g} / \mathrm{ml}$ streptomycin, and $0.5 \mathrm{~mm}$ L-glutamine for $24 \mathrm{~h}$ and then cultured in the same medium without FCS. The medium was changed three times per week by replacing $30 \%$ of the old medium with a fresh one. GluR $\delta 2-\mathrm{NTD}-\mathrm{Fc}-\mathrm{His}(120 \mu \mathrm{g})$ was preincubated with $\mathrm{F}\left(\mathrm{ab}^{\prime}\right)_{2}$ or Fab fragment of goat anti-human Fc antibody ( $39 \mu \mathrm{g}$; Jackson ImmunoResearch) for $3 \mathrm{~h}$. The cultures of cerebellar GCs at day 7 in vitro were incubated in medium containing GluR $\delta 2-N T D-F c-$ 

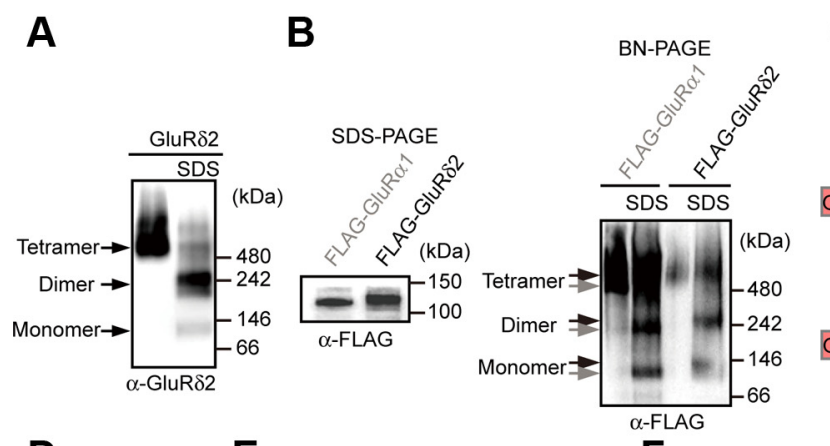

C

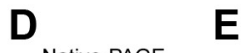

$\mathbf{E}$
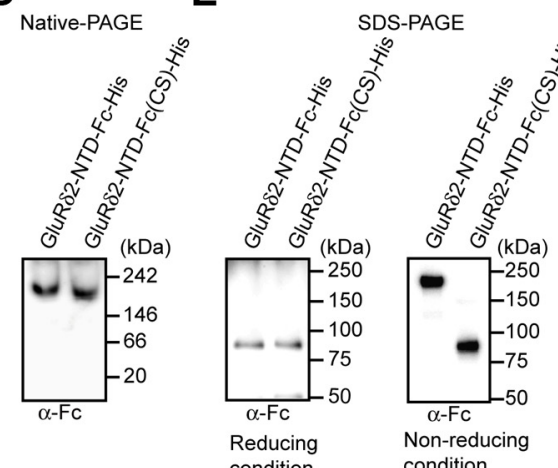

$\mathbf{F}$
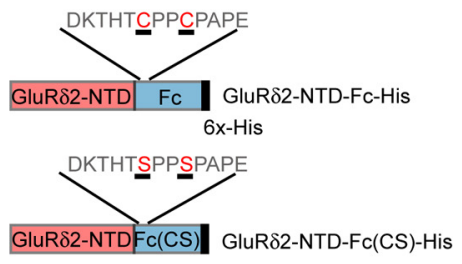

condition condition

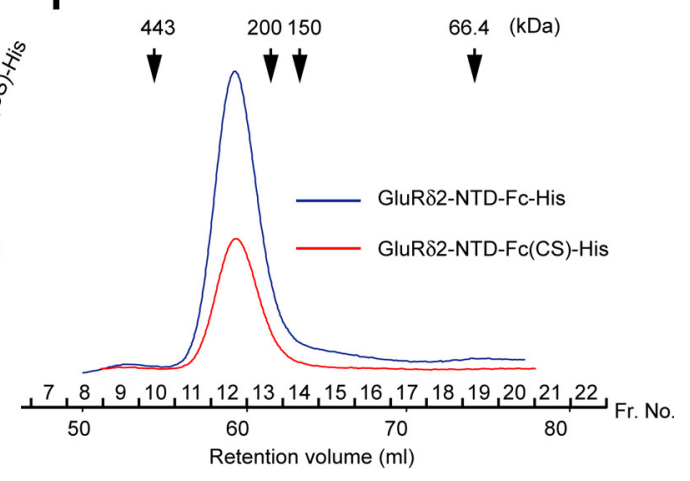

Figure 1. GluR $\delta 2$ forms a tetramer. A, BN-PAGE of GluR $\delta 2$, followed by immunoblotting with anti-GluR $\delta 2$ antibody. GluR $\delta 2$ was expressed in HEK293T cells, and the membrane fraction prepared from the transfected cells was loaded onto the gels with or without $1 \%$ SDS. B, SDS- and BN-PAGE of FLAG-GluR $\alpha 1$ and FLAG-GluR $\delta 2$, followed by immunoblotting with anti-FLAG antibody. FLAG-GluR $\alpha 1$ and FLAG-GluR $\delta 2$ were expressed in HEK293T cells, and membrane fractions prepared from the transfected cells were loaded onto the gels with or without $1 \%$ SDS. C,

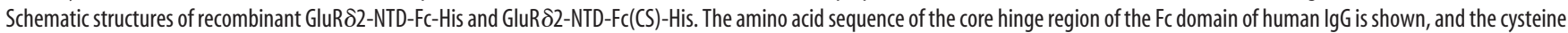

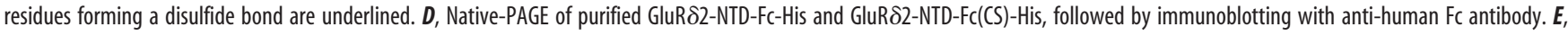

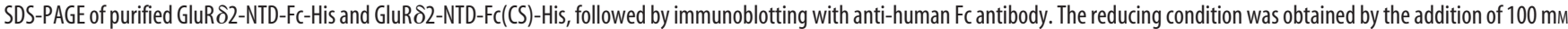

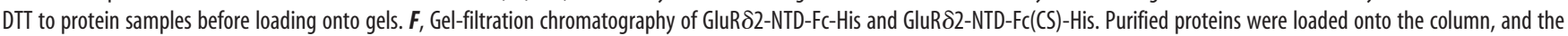
absorbance at $280 \mathrm{~nm}$ was monitored.

His treated with $\mathrm{F}\left(\mathrm{ab}^{\prime}\right)_{2}(13.25 \mu \mathrm{g} / \mathrm{ml})$, GluR $\delta 2-\mathrm{NTD}-\mathrm{Fc}-\mathrm{His}$ treated with Fab $(13.25 \mu \mathrm{g} / \mathrm{ml}), \mathrm{F}\left(\mathrm{ab}^{\prime}\right)_{2}(3.25 \mu \mathrm{g} / \mathrm{ml})$, or Fab $(3.25 \mu \mathrm{g} / \mathrm{ml})$. The effects of NRXN1 $\beta$-LNS-MH and HA-Cbln1 were examined at the concentrations of 30 and $10 \mu \mathrm{g} / \mathrm{ml}$, respectively. After $24 \mathrm{~h}$, cells were fixed with $4 \%$ paraformaldehyde and immunostained using rabbit anti-vesicular glutamate transporter 1 (VGluT1) (Miyazaki et al., 2003), goat anti-VGluT1 (Frontier Institute), guinea pig anti-Bassoon (Joo et al., 2011), mouse antiBassoon (Assay Designs), rabbit anti-microtubule-associated protein-2 (MAP2) (Millipore), mouse anti-postsynaptic density-95 (PSD-95) (Thermo Scientific), and anti-His (Millipore) antibodies as primary antibodies. For secondary antibodies, FITC-conjugated anti-human Fc $\gamma$ antibody (Jackson ImmunoResearch) and species-specific Alexa Fluor 488-, 555,- and 647-conjugated anti-IgG antibodies (Invitrogen) were used.

Image acquisition and quantification. Images of cultured GCs were collected from three separate experiments. Images were taken with a confocal laser-scanning microscope (TCS SP5; Leica) under constant conditions as to laser power, iris, gain, $z$-steps, and zoom setting throughout the experiments, and all quantitative measurements were performed with ImageJ 1.44 software. For the quantification of VGluT1 and Bassoon puncta along axons of GCs, $z$-series optical sections were projected by the brightest point method and smoothened by the rank filter method. VGluT1 and Bassoon puncta were defined as areas in which staining signal intensities were $\geq 1.5$ times stronger than those of background signals on the same field. Contiguous puncta were separated from each other by the "segmented particles" tool. The quantification was performed in a blind manner with respect to the recombinant proteins applied to the cultures. To measure the relationship between staining signals for Bassoon and GluR $\delta 2-\mathrm{NTD}-\mathrm{Fc}-\mathrm{His}$ in Figure $2 L$, Bassoon puncta merged with or juxtaposed to GluR $\delta 2-\mathrm{NTD}-\mathrm{Fc}-\mathrm{His}$ puncta were manually traced so that both puncta were included. The signal intensities for GluR82-NTD-Fc-His and Bassoon within the traced area were plot- ted as a scatter plot, and their correlation was evaluated with Pearson's correlation coefficient.

Images of HEK293T cells expressing wild-type or mutant NRXN1 $\beta$-V5 were collected from two separate experiments. The intensities of immunostained signals for HA-Cbln 1 and NRXN1 $\beta$-V5 were measured as the optical mean density within the manually traced area enclosing HEK293T cells.

Statistical significance was evaluated by one-way ANOVA followed by post hoc Tukey's test, Dunnett's test, or $t$ test.

\section{Results}

\section{Tetrameric assembly of GluR $\delta 2$}

We transfected an expression vector for GluR $\delta 2$ to HEK293T cells. Membrane proteins prepared from the transfected cells were subjected to BN-PAGE followed by immunoblotting with anti-GluR $\delta 2$ antibody. We detected GluR $\delta 2$ band with smearing at the position corresponding to the MW of the tetramer (Fig. $1 A)$. In the presence of $1 \%$ SDS, the GluR $\delta 2$ band collapsed into monomeric and dimeric intermediates. Because there is good evidence for tetrameric assembly of the AMPA-type GluR (Rosenmund et al., 1998; Bowie and Lange, 2002; Penn et al., 2008), we also compared the mobility of GluR $\delta 2$ with that of AMPA-type GluR $\alpha 1$ on SDS- and BN-PAGE. Both GluR $\delta 2$ and GluR $\alpha 1$ were tagged with the FLAG epitope at their N termini (FLAG-GluR $\alpha 1$ and FLAG-GluR $\delta 2$ ) and were expressed in HEK293T cells. When membrane proteins prepared from the transfected cells were subjected to SDS-PAGE, FLAG-GluR $\alpha 1$ and FLAG-GluR $\delta 2$ were detected as $\sim 105$ and $115 \mathrm{kDa}$ bands, respectively (Fig. $1 B$ ). On BN-PAGE, both FLAG-GluR $\alpha 1$ and FLAG-GluR $\delta 2$ were found at the positions corresponding to 
A

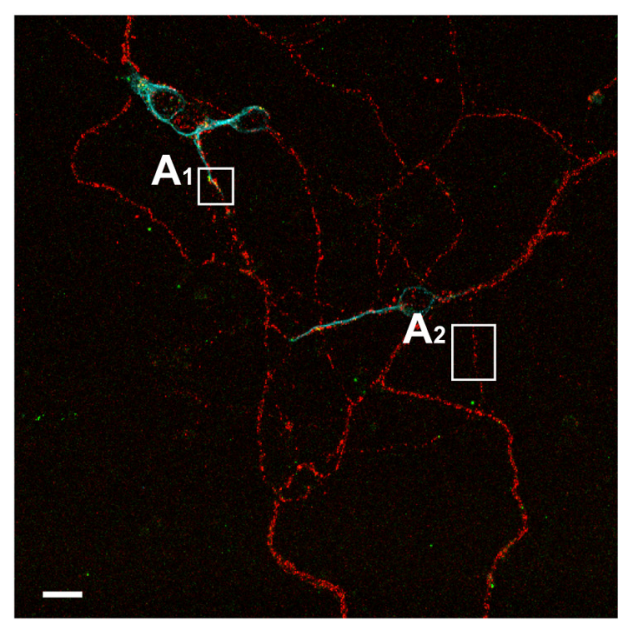

B

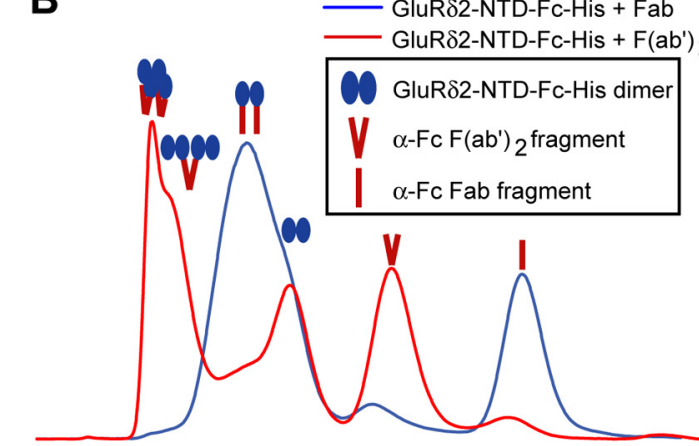

$12345678910111213141516171819202122232425262728 \mathrm{Fr}$.

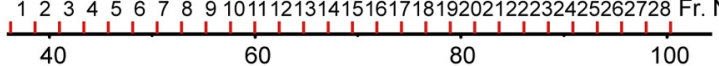

Retention volume (ml)

D

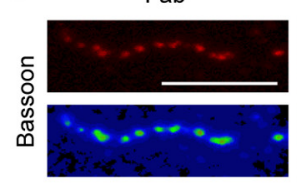

E

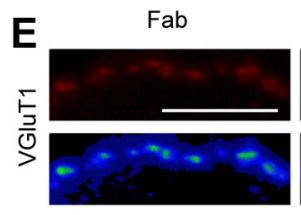

$\mathbf{F}$

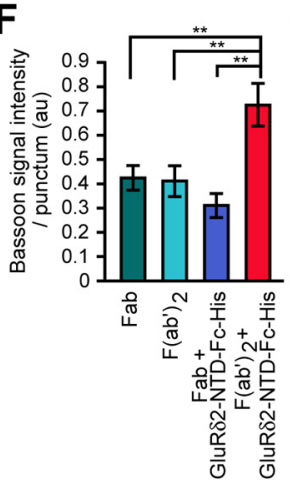

$\mathrm{F}(\mathrm{ab})_{2}$

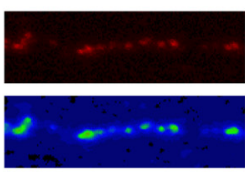

$\mathrm{F}\left(\mathrm{ab} \mathrm{b}^{\prime}\right)_{2}$

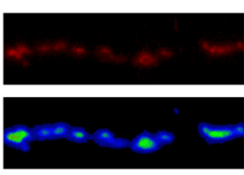

G

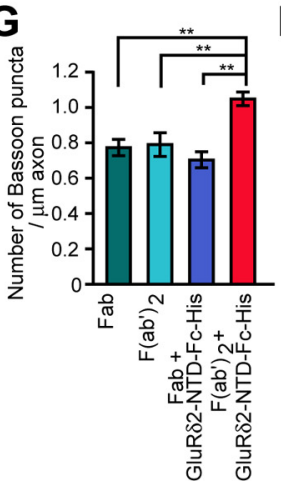

$\mathbf{A}_{1}$
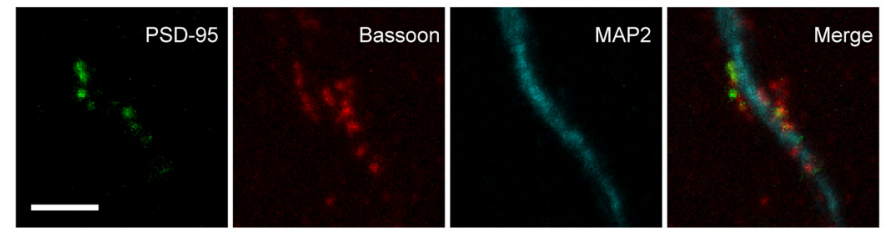

$\mathrm{A}_{2}$
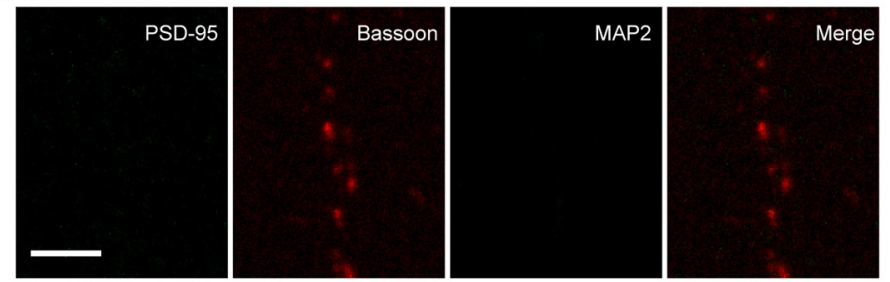

C

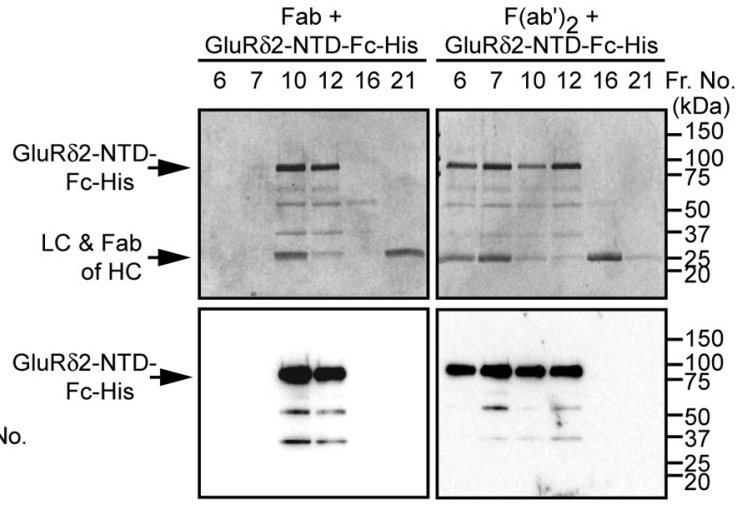

$\mathrm{F}(\mathrm{ab})_{2}+$

$\mathrm{Fab}+$

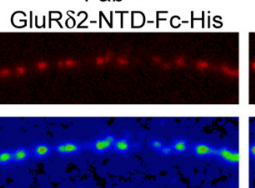

$\mathrm{Fab}+$ GluRס2-NTD-Fc-His

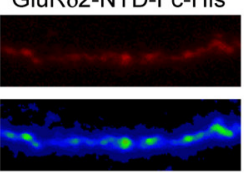

H

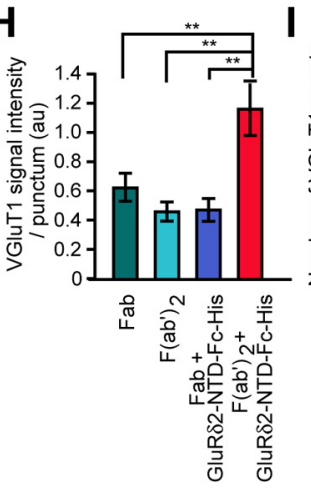

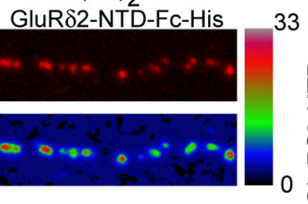

$\mathrm{F}\left(\mathrm{ab}^{\prime}\right)_{2}+$
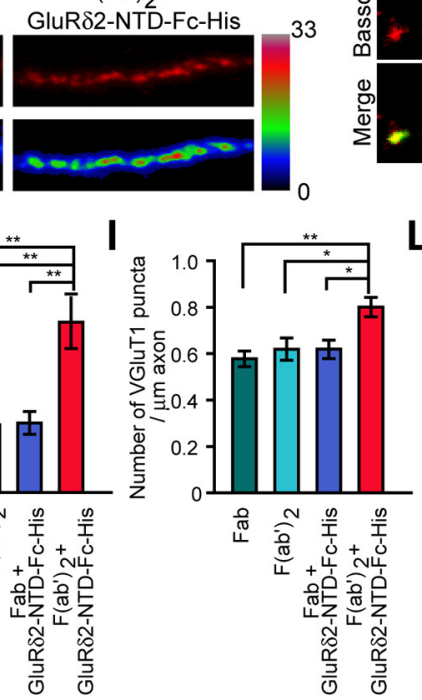

$\left.\mathrm{F}(\mathrm{ab})_{2}\right)_{2}+$

K

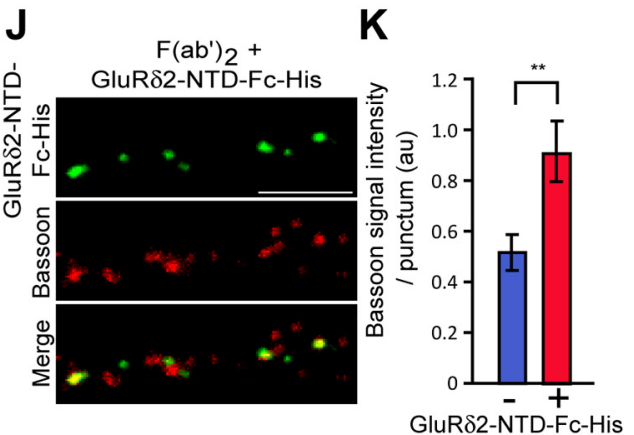

$\mathbf{L}$

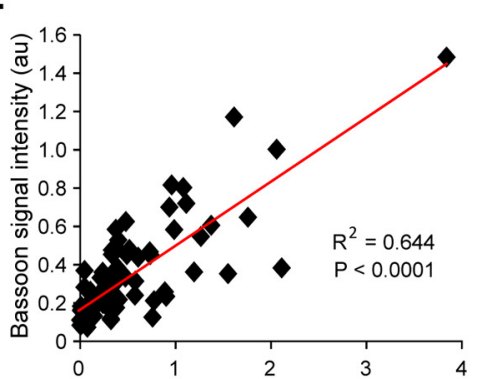

GluR82-NTD-Fc-His signal intensity (au)

Figure 2. Presynaptic differentiation is induced by the tetramer of GluR $\delta 2-N T D$ but not by the dimer. A, Immunostaining for MAP2, PSD-95, and Bassoon in cultured cerebellar GCs. For boxed areas, higher-magnification images are shown $\left(\boldsymbol{A}_{1}, \boldsymbol{A}_{2}\right) . \boldsymbol{B}, \boldsymbol{C}$, The tetramer of GluR $\delta 2$-NTD-Fc-His is formed by the treatment with $\mathrm{F}\left(\mathrm{ab}^{\prime}\right)_{2}$ fragment of anti-Fc antibody. Gel-filtration chromatog-

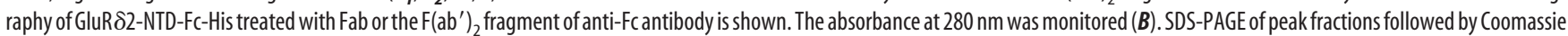
staining (top) and immunoblotting with anti-Fc antibody (bottom) is shown (C). LC, light chain parts of Fab and $F\left(a b^{\prime}\right)_{2}$ fragments; $H C$, heavy chain parts of Fab and F(ab') fragments. $\boldsymbol{D}, \boldsymbol{E}$,

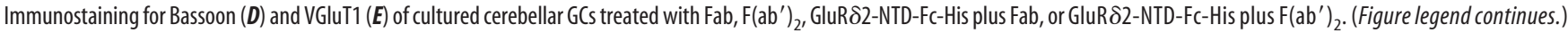


A

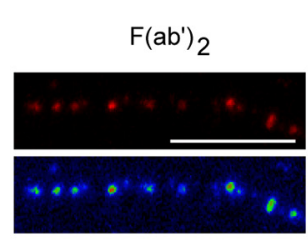

B

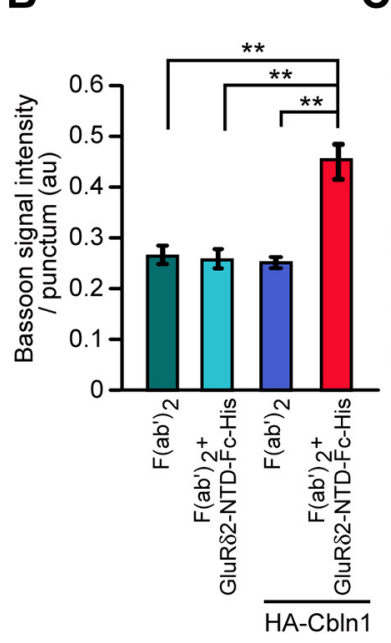

C

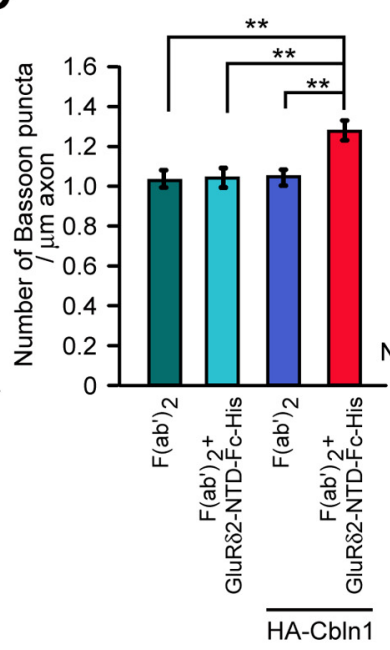

D

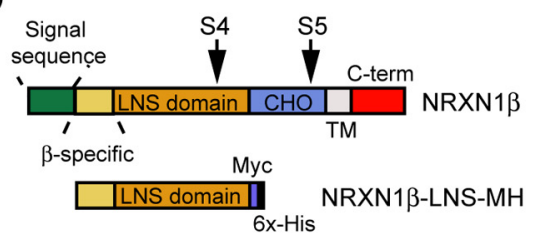

E

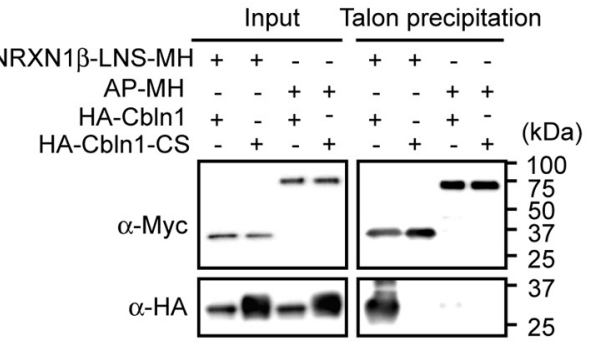

F

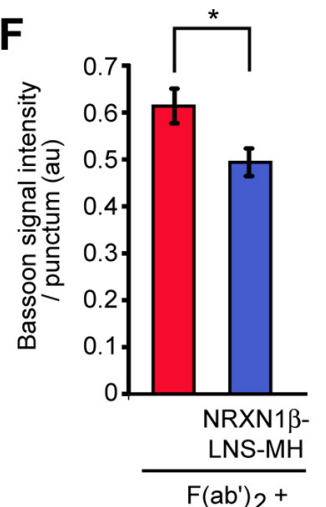

$\mathrm{F}\left(\mathrm{ab} \mathrm{b}^{\prime}\right)_{2}+$ GluR82-NTD-Fc-His

G

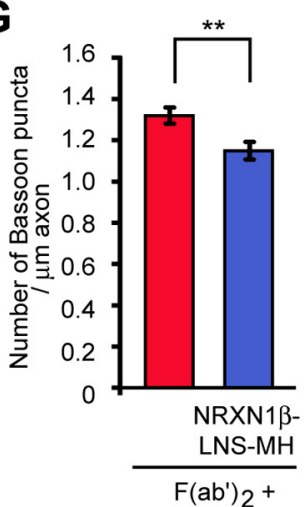

GluR 2 2-NTD-Fc-His

Figure 3. Tetrameric GluR $\delta 2$-NTD requires NRXN and Cbln1 for induction of presynaptic differentiation of cultured cerebellar GCs prepared from Cbln1 knock-out mice. $A$, Immunostaining for

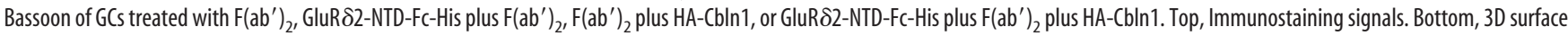
plot vertical images. $\boldsymbol{B}, \boldsymbol{C}$, Intensities of punctate staining signals for Bassoon $(\boldsymbol{B})$ and numbers of Bassoon puncta $(\boldsymbol{C})$ along axons of $\mathrm{GC}\left(\mathrm{s}\right.$ treated with $\mathrm{F}\left(\mathrm{ab}^{\prime}\right)_{2}, \mathrm{GluR} \delta 2-\mathrm{NTD}-\mathrm{Fc}-\mathrm{His}_{\mathrm{s}}$ plus $\mathrm{F}\left(\mathrm{ab}{ }^{\prime}\right)_{2}, \mathrm{~F}\left(\mathrm{ab}^{\prime}\right)_{2}$

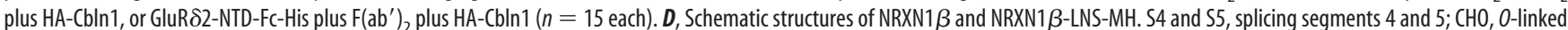
glycosylation region; TM, transmembrane segment. E, Pull-down assay for the interaction between NRXN1 $\beta$-LNS-MH and HA-Cbln1. Alkaline phosphatase (AP)-MH and HA-Cbln1-CS (Uemura et al., 2010) served as controls. $\boldsymbol{F}, \boldsymbol{G}$, Intensities of punctate staining signals for Bassoon $(\boldsymbol{F})$ and numbers of Bassoon puncta $(\boldsymbol{G})$ along axons of $G\left(s\right.$ treated with $G$ luR $\delta 2$-NTD-Fc-His plus $F\left(\text { ab }^{\prime}\right)_{2}$ in the presence or absence of NRXN1 $\beta$-LNS-MH $\left(n=15\right.$ each). All values represent mean \pm SEM. ${ }^{*} p<0.05$; ${ }^{* *} p<0.01$; Tukey's test $(\boldsymbol{B}, \boldsymbol{C}), t$ test $(\boldsymbol{F}, \boldsymbol{G})$. Scale bar, $5 \mu \mathrm{m}$.

their tetrameric complexes, whereas collapsed dimeric and monomeric intermediates were observed in the presence of $1 \%$ SDS (Fig. $1 B$ ). These results suggest that GluR $\delta 2$ assembles as a tetramer in the membrane.

The N-terminal domain (NTD) of GluR $\delta 2$ (GluR $\delta 2-N T D)$ is required and sufficient for induction of presynaptic differentiation and interaction with presynaptic NRXNs through Cbln1 (Uemura and Mishina, 2008; Uemura et al., 2010). We expressed GluR $\delta 2-N T D$ as a fusion protein with the Fc-domain of human

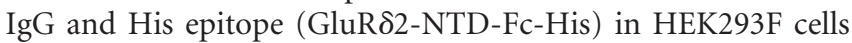
(Fig. 1C). The fusion protein secreted in the culture medium was

\footnotetext{
(Figure legend continued.) Top, immunostaining signals. Bottom, 3D surface plot vertical images. $\boldsymbol{F}, \boldsymbol{G}$, Intensities of punctate staining signals for Bassoon $(\boldsymbol{F})$ and numbers of Bassoon puncta $(G)$ along axons of cultured cerebellar GCs treated with Fab, $F\left(a^{\prime}{ }^{\prime}\right)_{2}$, GluR $\delta 2$-NTD-Fc-His plus Fab, or GluR $\delta 2-N T D-F c-H i s$ plus F(ab' $)_{2}(n=18$ each). $\boldsymbol{H}, \boldsymbol{I}$, Intensities of punctate staining signals for VGluT1 $(\boldsymbol{H})$ and numbers of VGluT1 puncta $(\boldsymbol{I})$ along axons of cultured cerebellar GCS

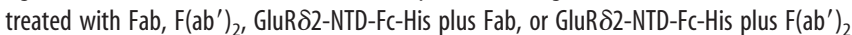
( $n=18$ each). J, Immunostaining for GluRס2-NTD-Fc-His and Bassoon of cultured cerebellar GCs treated with GluR $\delta 2-N T D-F c-H i s ~ p l u s ~ F\left(a b^{\prime}\right)_{2}$. $\boldsymbol{K}$, Intensities of punctate staining signals for Bassoon with or without juxtaposing GluRס2-NTD-Fc-His signals along axons of cultured cerebellar GCs treated with GluR $\delta 2-N T D-F c-H i s ~ p l u s ~ F(a b ')_{2}(n=58$ each). L, Scatter plot of inten-

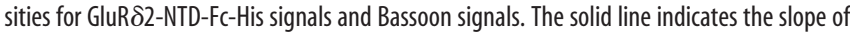
linear correlation $(p<0.0001 ; n=86)$. GraphPad Prism 5 was used to generate the trend line and to calculate Pearson's $R^{2}$ and $p$ values. All values represent mean \pm SEM. ${ }^{*} p<0.05$; ${ }^{* *} p<0.01$; Tukey's test $(\boldsymbol{F}-\boldsymbol{I}), t$ test $(\boldsymbol{K})$. Scale bars: $\boldsymbol{A}, 10 \mu \mathrm{m} ; \boldsymbol{D}, \boldsymbol{E}, 5 \mu \mathrm{m} ; \boldsymbol{A}_{1}, \boldsymbol{A}_{2}, \boldsymbol{J}, 2.5 \mu \mathrm{m}$.
}

purified with Talon metal affinity resin and subjected to PAGE. On native-PAGE, a protein band of $\sim 180 \mathrm{kDa}$ was found by immunoblot analysis with an anti-Fc antibody (Fig. $1 D$ ). On the other hand, the size of monomeric GluR $\delta 2-N T D-F c-H i s ~ e s t i-$ mated by SDS-PAGE under the reducing condition was $\sim 90$ $\mathrm{kDa}$, which was close to the calculated MW of the fusion protein $(79 \mathrm{kDa})$ (Fig. $1 E)$. These results suggest that GluR $\delta 2-N T D-F c-$ His formed a dimer. It is possible that the formation of dimeric

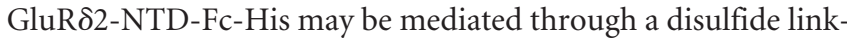
age of $\mathrm{Fc}$, since a protein band of $\sim 180 \mathrm{kDa}$ was found on SDSPAGE under the nonreducing condition. We then produced GluR $22-N T D-F c(C S)-H i s$, in which two cysteine residues of the core hinge region of $\mathrm{Fc}$ were substituted to serine residues (Fig. $1 C)$, to examine whether GluR $\delta 2-\mathrm{NTD}$ is dimeric by itself. GluR $\delta 2-N T D-F c(C S)$-His showed a protein band of $\sim 180 \mathrm{kDa}$ on native-PAGE and $\sim 90 \mathrm{kDa}$ on SDS-PAGE, both under reducing and nonreducing conditions (Fig. 1D,E). Thus, GluR $\delta 2-$ $\mathrm{NTD}-\mathrm{Fc}(\mathrm{CS})$-His lacking the disulfide linkage of Fc formed a dimer, suggesting that dimerization was mediated by GluR $\delta 2$ NTD. In an FPLC gel-filtration assay, the apparent sizes of dimeric GluR $\delta 2-N T D-F c-H i s$ and GluR $\delta 2-N T D-F c(C S)-H i s ~ e s-$ timated using MW standards as references (data not shown) were $\sim 280 \mathrm{kDa}$ (Fig. $1 F$ ). The discrepancy between the sizes of the GluR $\delta 2-N T D$ dimer obtained in the FPLC assay and the calculated MW ( $159 \mathrm{kDa})$ may be ascribed to the fact that the estimation of MW by gel-filtration is strongly affected by the overall 
A

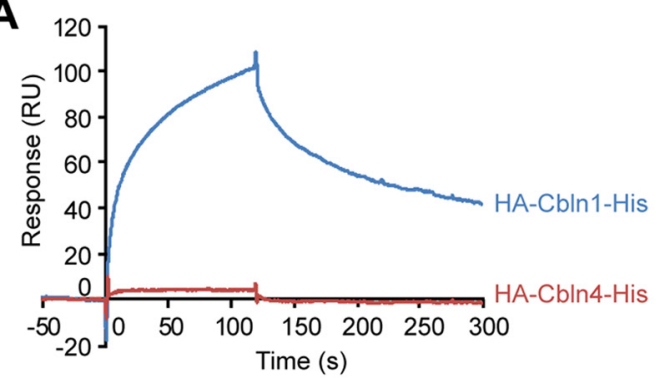

C

Signal sequence

\section{B}

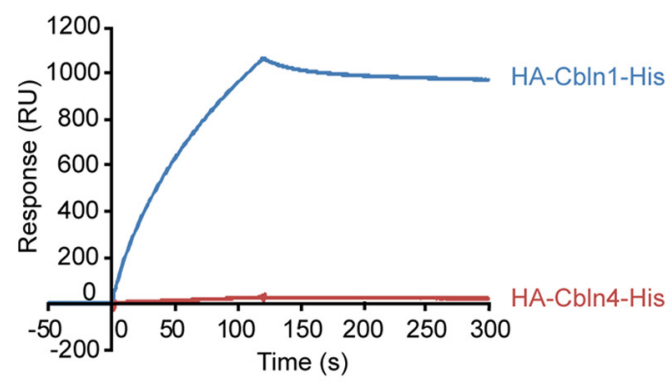

$55 \quad 62 \quad \prod_{\text {HA }}^{23}$ C19 domain ${ }_{6 x-H i s}^{193}$ HA-Cbln1-His

mCbln 1 MLGVVELLLLGTAWLAGPARGQNETEPIVLEGKCLVVCDSNPTSDPTGTA - - LGISVRSGSAKVAFSAI mCbIn4 MGSARRALSVVPAVLIILVLPVWAQNDTEPIVLEGKCLVVCDSNPATDSKGSSSSPLGISVRAANSKV:AFSAV C1q domain 103

mCbln 1 RSTNHEPSEMSNRTMIIYFDQVLVNIGNNFDSERSTFIAPRKGIYSFNFHVVKVYNRQTIQVSLMLNGWPVIS MCbII 4 RSTNHEPSEMSNKTRIIYFDQILVNVGNFFTLE-SV:FVAPRKGIYSFSFHVIKVYQSQTIQVNLMLNGKPVIS

146

mCbln 1 AFAGDQDVTREAASNGVLIOMEKGDRAYLKLERGNLMGGWKYSTFSGFLVFPI mCbln4 AFAGDKDVTREAATNGVLLYLDKEDKVYLKLEKGNLIGGWOYSTFSGFLVFPI
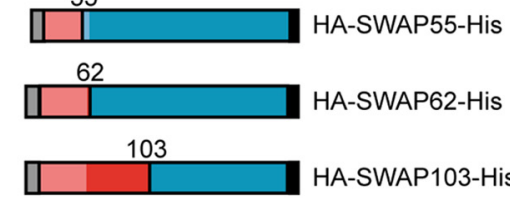

HA-SWAP62-His

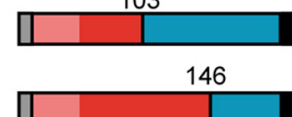

HA-SWAP103-His

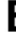

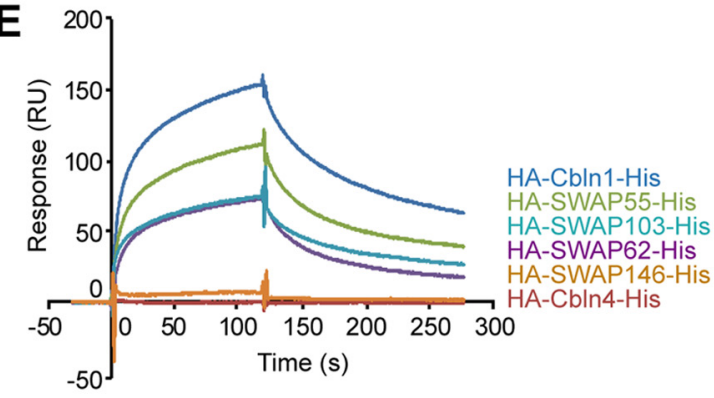

G

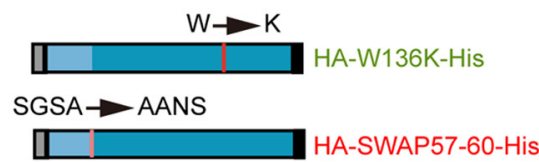

H

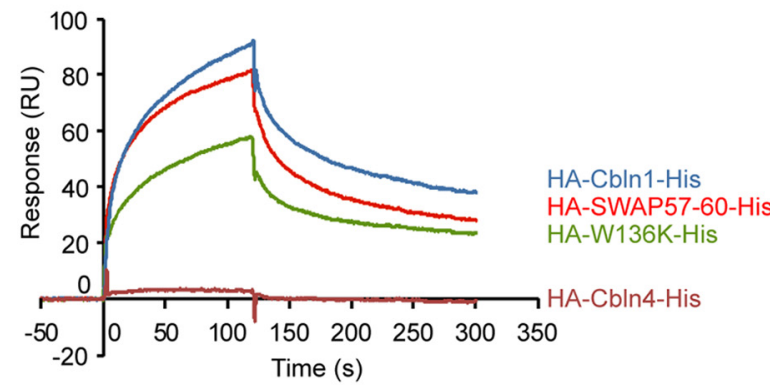

I

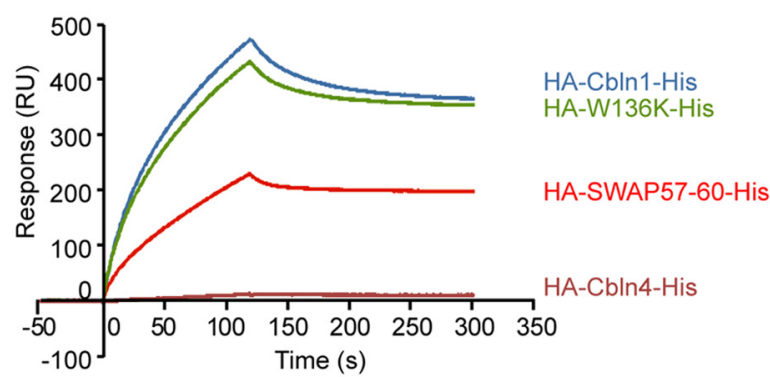

$\mathbf{F}$

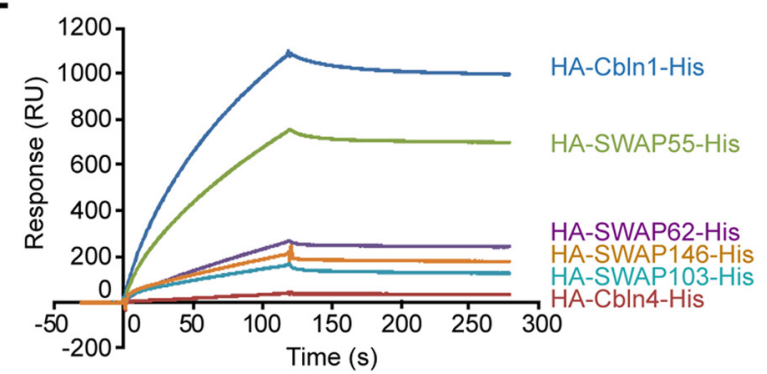

$\mathbf{J}$
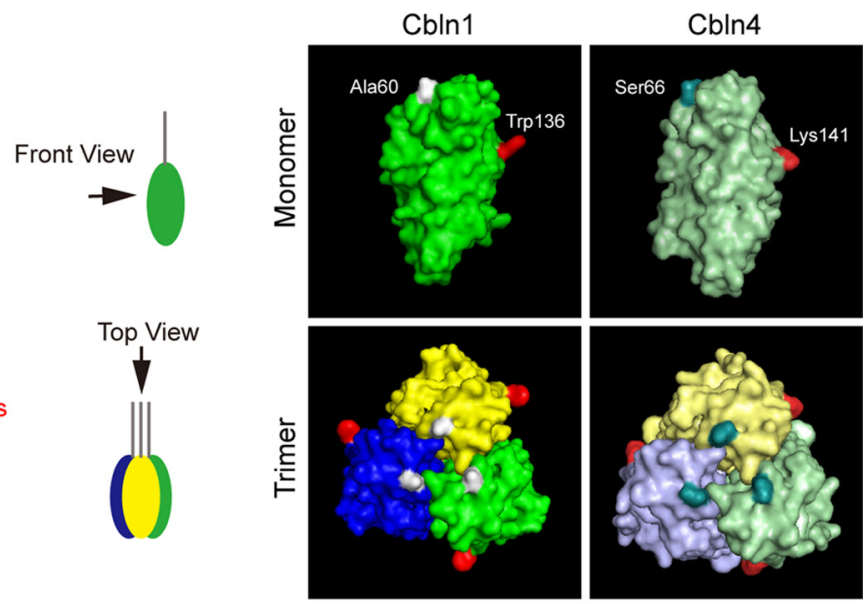

K
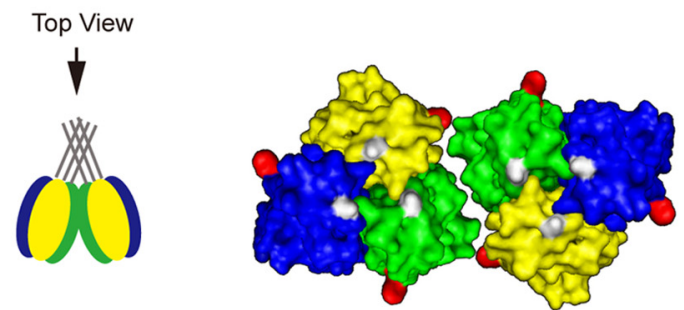

Figure 4. Critical regions are differential for the interaction of Cbln1 with GluR $\delta 2$ or NRXN1 $\beta$. $\boldsymbol{A}, \boldsymbol{B}$, SPR sensorgrams of $250 \mathrm{~nm}$ HA-Cbln1-His and HA-Cbln4-His over GluR $\delta 2-N T D-F c(\boldsymbol{A})$ and NRXN1 $\beta$-ECD-Fc $(\boldsymbol{B})$ captured on the surface of the sensor chip. $\boldsymbol{C}$, Alignment of the amino acid sequences of Cbln1 and Cbln4. Red and blue lines indicate the signal (Figure legend continues.) 
shape of molecules (Andrews, 1964). These results suggest that GluR $\delta 2$ assembles as a tetramer and the NTD of GluR $\delta 2$ contributes to dimer formation.

\section{Tetramerization is required for GluR $\delta 2$-NTD to induce presynaptic differentiation}

The axons of cultured cerebellar GCs with immunostaining signals for active zone protein Bassoon (Fig. 2A) and synaptic vesicle protein VGluT1 (data not shown) were rarely intermingled with their dendrites with MAP2 immunostaining signals. Consistently, the majority of GC axons with strong signals for presynaptic markers showed no detectable signals for postsynaptic marker PSD-95, except that a few signals for PSD-95 merged with Bassoon signals were detectable in a small fraction of GC dendrites (Fig. 2A). These observations are consistent with previous reports that the majority of varicosities containing presynaptic proteins of cultured cerebellar GCs are not apposed to definite postsynaptic structures (Marxen et al., 1999; Urakubo et al., 2003), whereas functional synapses may be formed in a small portion of cultured GC axons as synaptic transmission was detected in cultured GCs (Losi et al., 2002; Lu et al., 2006).

To examine whether the tetrameric assembly of GluR $\delta 2$ is essential for triggering the presynaptic differentiation, we compared the effects of dimeric and tetrameric complexes of GluR $\delta 2$ NTD on the accumulation of Bassoon and VGluT1 on the axons of cultured cerebellar GCs. When incubated with the $\mathrm{F}\left(\mathrm{ab}^{\prime}\right)_{2}$ fragment of anti-human Fc antibody for $3 \mathrm{~h}$, most of GluR $\delta 2$ NTD-Fc-His became tetramerized (Fig. 2B,C). On the other

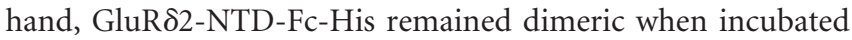
with the Fab fragment of anti-human $\mathrm{Fc}$ antibody. We thus used GluR $\delta 2$-NTD-Fc-His treated with $\mathrm{F}\left(\mathrm{ab}^{\prime}\right)_{2}$ and Fab as tetrameric and dimeric GluR $\delta 2-\mathrm{NTD}$, respectively, in subsequent experiments. Cultured GCs were incubated with tetrameric or dimeric GluR $\delta 2-N T D-F c-H i s$ for $24 \mathrm{~h}$ and were then immunostained with an antibody against Bassoon (Fig. 2D). GCs incubated with $\mathrm{F}\left(\mathrm{ab}^{\prime}\right)_{2}$ or Fab fragment served as controls. The intensity of punctate staining signals for Bassoon was increased approximately twofold in GC axons incubated with tetrameric GluR $\delta 2$-NTDFc-His compared with that in control GC axons $(p<0.01)$ (Fig. $2 F)$. In contrast, there were no significant differences in the intensity of Bassoon staining signals between GCs incubated with

\footnotetext{
$\leftarrow$

(Figure legend continued.) sequence and C1q domain, respectively. Dotted vertical lines show the junctions of chimeras between $\mathrm{Cb} \ln 1$ and $\mathrm{Cb} \ln 4$; the numbers indicate those of the $\mathrm{N}$-terminal amino acid residues of $\mathrm{Cb} \ln 1$ sequences in the chimeras. $D$, Schematic structures of chimeras between $\mathrm{Cbln} 1$ and $\mathrm{Cbln} 4$. E, $\boldsymbol{F}$, SPR sensorgrams of HA-Cbln1-His, HA-Cbln4-His and chimeras over GluR $\delta 2-N T D-F c(E)$ and NRXN1 $\beta-E C D-F c(F)$ captured on the surface of the sensor chip. Concentrations of analytes were $250 \mathrm{~nm}$. G, Schematic structures of Cbln1 mutants W136K and SWAP57-60. $\boldsymbol{H}, \boldsymbol{I}$, SPR sensorgrams of HA-Cbln1-His, HA-Cbln4-His, HA-W136K-His, and HA-SWAP57-60-His over GluR $22-N T D-F c(\boldsymbol{H})$ and NRXN1 $\beta$-ECD-Fc $(\boldsymbol{I})$ captured on the surface of the sensor chip. Concentrations of analytes were $250 \mathrm{~nm}$. J, Solid surface structure models of the $C 1 q$ domains of monomeric (top) and trimeric (bottom) Cbln1 and Cbln4. Ala60 and Trp136 of $\mathrm{Cb} \ln 1$ are indicated by white and red, respectively, and Ser66 and Lys 141 of $\mathrm{Cbln} 4$ are indicated by dark green and brown, respectively. Residues Ser $57, \mathrm{Gly} 58$, and Ser59 are not included in the model. The structural models were generated with SWISS-MODEL (Arnold et al., 2006) (http://swissmodel.expasy.org/). The amino acid sequences of Cbln1 (residues 60-193) and Cbln4 (residues 66-198) were submitted to SwissModel Automatic Modeling Mode (http:// swissmodel.expasy.org/workspace/index.php?func = modeling simple1). The structure of the collagen XNC1 domain trimer (PDB ID 1gr3A) (Bogin et al., 2002) was selected as a template for modeling. The obtained alignment was imported into Swiss-Pdb Viewer 4.0.1 (N. Guex and M. C. Peitsch, 1997; http://www.expasy.org/spdbv/) and Pymol (http://www.pymol.org/) and was manually optimized. $\boldsymbol{K}$, Structural model of Cbln 1 hexamer. Two Cbln 1 trimers were manually aligned.
}

dimeric GluR $\delta 2$-NTD-Fc-His and control GCs. Furthermore, the number of Bassoon puncta along the axon was significantly increased in GCs incubated with tetrameric GluR $\delta 2-N T D-F c-$ His compared with that in control GCs $(p<0.01)$ (Fig. $2 G)$. On the other hand, there were no significant differences in the number of Bassoon puncta between GCs incubated with dimeric GluR $\delta 2-N T D-F c-H i s$ and control GCs.

We also examined the effects of the treatment of cultured GCs with tetrameric and dimeric GluR $\delta 2$-NTD on the accumulation of synaptic vesicles by immunostaining of VGluT1 (Fig. 2E). The intensity of punctate staining signals for VGluT1 was increased approximately twofold in GC axons incubated with tetrameric GluR $\delta 2-\mathrm{NTD}-\mathrm{Fc}-\mathrm{His}$ compared with that in control GC axons $(p<0.01)$ (Fig. $2 H)$. In contrast, there were no significant differences in the intensity of VGluT1 staining signals between GCs incubated with dimeric GluR $\delta 2-N T D-F c-H i s$ and control GCs. The number of VGluT1 puncta along the axon was significantly increased in GCs incubated with tetrameric GluR $\delta 2-\mathrm{NTD}-\mathrm{Fc}-\mathrm{His}$ compared with that in control GCs $(p<0.01$ or $<0.05)$ (Fig. 2I). On the other hand, there were no significant differences in the number of VGluT1 puncta between GCs incubated with dimeric GluR $\delta 2-N T D-F c-H i s$ and control GCs.

We confirmed the presence of immunostaining signals for GluR $\delta 2-N T D-F c-H i s$ along GC axons treated with tetrameric

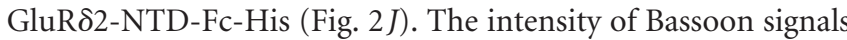
was much stronger in puncta merged with or juxtaposed to tetrameric GluR $\delta 2-\mathrm{NTD}-\mathrm{Fc}-\mathrm{His}$ signals than in those without any merged signals on the same GC axons $(p<0.01)$ (Fig. $2 K$ ). Furthermore, the intensities of Bassoon signals on respective puncta correlated well with those for tetrameric GluR $\delta 2$-NTDFc-His (Pearson's $R^{2}=0.644 ; p<0.0001$ ) (Fig. $2 L$ ). These results suggest that tetramer formation is essential for GluR $\delta 2$ NTD to induce presynaptic differentiation.

\section{Tetrameric GluR $\delta 2$-NTD induces presynaptic differentiation by interacting with Cbln1 and NRXN}

Postsynaptic GluR $\delta 2$ mediates PF-PC synapse formation in the cerebellum by interacting selectively with presynaptic NRXN variants containing $S 4$ through Cbln1 (Uemura et al., 2010). As expected, tetrameric GluR $\delta 2-\mathrm{NTD}-\mathrm{Fc}$-His failed to exert any effect on the accumulation of Bassoon puncta in the axons of cultured GCs prepared from Cbln1 knock-out mice (Fig. 3A-C). However, the addition of Cbln1 tagged with HA epitope at the $\mathrm{N}$ terminus (HA-Cbln1) to the culture restored the activity of tetrameric GluR $\delta 2-\mathrm{NTD}-\mathrm{Fc}$-His to stimulate the presynaptic differentiation. The extracellular domain (ECD) of NRXN1 $\beta$ $(\mathrm{NRXN1} \beta$-ECD) is composed of the laminin-neurexin-sex hormone-binding globulin (LNS) domain and the O-linked glycosylated stretch (Ushkaryov et al., 1992; Missler and Südhof, 1998). The LNS domain of NRXN $1 \beta$ containing S4 (NRXN1 $\beta$ LNS) conjugated with Myc and His epitopes at the $\mathrm{C}$ terminus (NRXN1 $\beta$-LNS-MH) was sufficient to interact with HA-Cbln1 (Fig. $3 D, E$ ). The addition of NRXN1 $\beta$-LNS-MH, which would compete with endogenous NRXNs for binding to Cbln1, significantly reduced the intensity and number of punctate staining signals for Bassoon along the axons of GCs incubated with tetrameric GluR $\delta 2-N T D-F c-H i s$ (Fig. 3F,G). These results suggest that tetrameric GluR $\delta 2-N T D$ requires Cbln1 and NRXN for induction of presynaptic differentiation. 
A
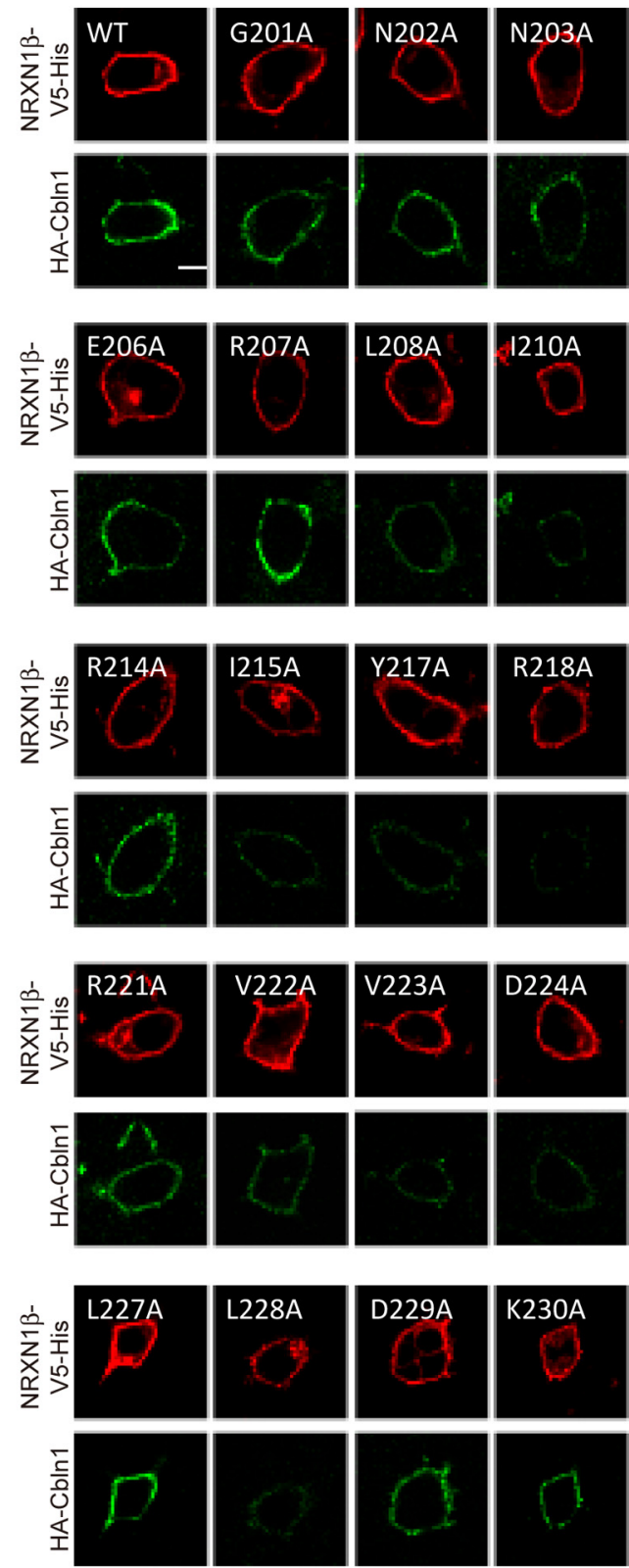

B
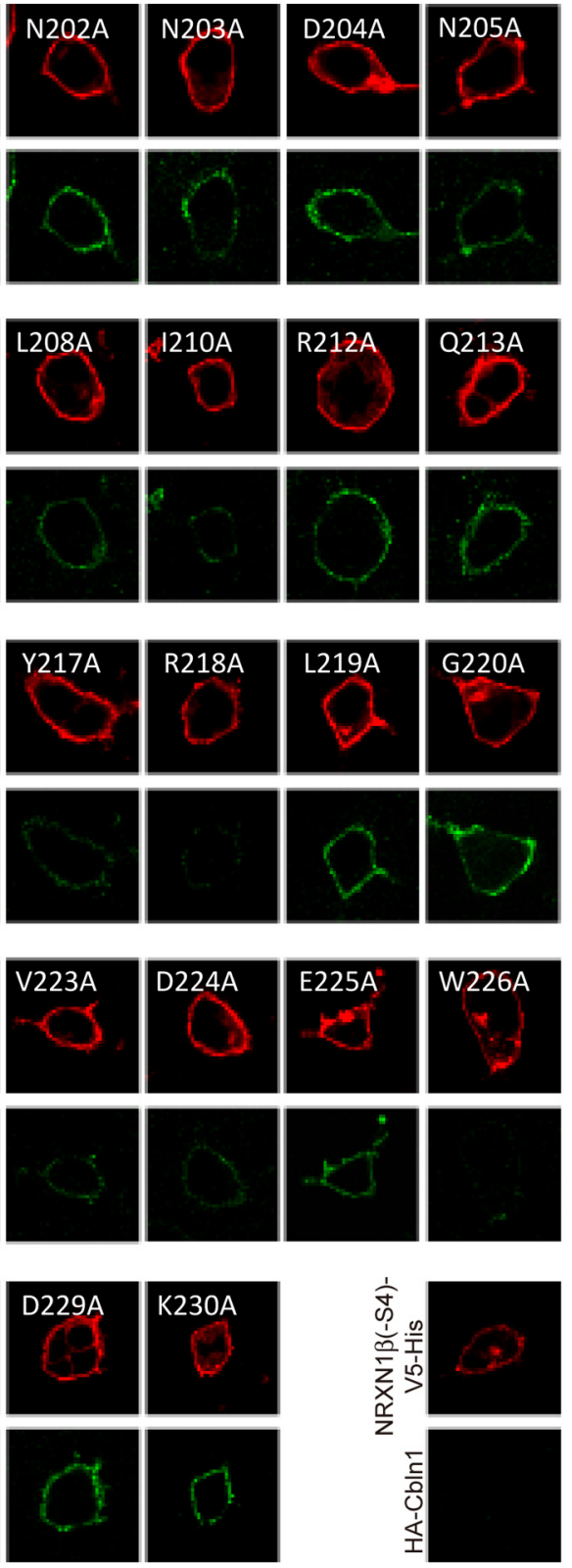

Bound HA-Cbln1 signal intensity (AU) HA-Cbln1 / NRXN1 1 -V5-His

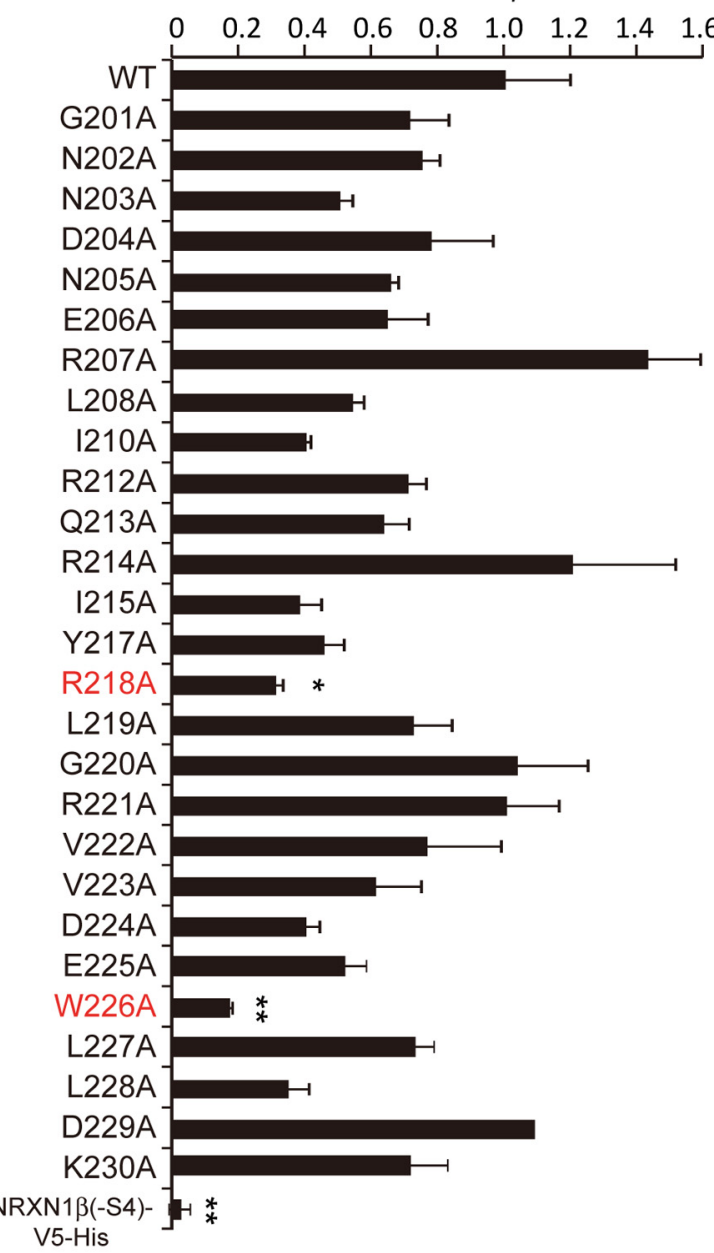

C

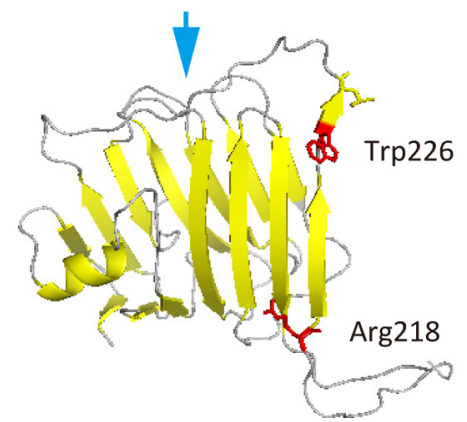

Figure 5. Effect of alanine substitution mutations of $S 4$ on the interaction of NRXN1 $\beta$ with Cbln1. A, Binding of HA-Cbln1 to HEK293T cells transfected with wild-type and mutant NRXN1 $\beta$-V5. Scale bar, $10 \mu \mathrm{m}$. $\boldsymbol{B}$, Intensities of HA-Cbln1 signals $\left(n=5\right.$ each). All values represent mean \pm SEM. ${ }^{*} p<0.05$; ** $p<0.01$; Dunnett's test. C, Diagram of crystal structure of NRXN1 $\beta$ (PDB ID 3MW2). Arg218 and Trp226 are indicated in red. The blue arrow indicates the interface for NLGN binding.

Differential effects of Cbln1 mutations on binding affinities for GluR $\delta 2$ and NRXN1 $\beta$

We thus examined the assembly stoichiometry of the GluR $\delta 2$ Cbln1-NRXN trans-synaptic triad to understand how tetrameric GluR $\delta 2$ triggers synaptogenic signaling. Since no direct interaction between GluR $\delta 2$ and NRXNs was detectable and Cbln1 bound to both GluR $\delta 2-N T D$ and NRXN1 $\beta$-ECD, we proposed a linear trans-synaptic triad of GluR $\delta 2-C b \ln 1-N R X N$ as the synaptogenic organizer of the PF-PC synapse (Uemura et al., 2010). To confirm the model, we first asked whether distinct regions of Cbln 1 are responsible for binding to GluR $\delta 2$ and NRXN1 $\beta$. SPR binding analysis revealed a large difference in the binding affinities for GluR $\delta 2-N T D-F c$ and NRXN1 $\beta$-ECD-Fc between Cbln 1 and Cbln 4 tagged with $\mathrm{HA}$ and His epitopes at the $\mathrm{N}$ and $\mathrm{C}$ termini, respectively (HA-Cbln1-His and HA-Cbln4-His) (Fig. $4 A, B$ ), despite $73.6 \%$ amino acid sequence identity (Fig. $4 C$ ).

We thus constructed a series of swap mutants (SWAP55, 62, 103, and 146) between HA-Cbln1-His and HA-Cbln4-His (Fig. $4 D$ ). These chimeras formed hexamers, as confirmed on BNPAGE (data not shown), and had intermediate affinities for GluR $\delta 2-N T D-F c$ and NRXN1 $\beta$-ECD-Fc compared with HACbln1-His and HA-Cbln4-His (Fig. 4E,F). However, the effects 
of the mutations on the binding to GluR $\delta 2-N T D-F c$ and NRXN1 $\beta$-ECD-Fc were differential. There was a large difference in the affinity for GluR $\delta 2-\mathrm{NTD}-\mathrm{Fc}$ between HA-SWAP103-His and HASWAP146-His (Fig. 4E). In contrast, a strong decrease in the affinity for NRXN1 $\beta$-ECD-Fc was found between HA-SWAP55-His and HA-SWAP62-His (Fig. $4 F$ ).

There are eight amino acid differences between SWAP103 and SWAP146. Among these residues, we focused on Trp136 of Cbln 1 because the corresponding position of Cbln 4 is lysine and thus constructed the W136K substitution mutant of Cbln1 (Fig. 4G). On the other hand, four consecutive amino acids are different between SWAP55 and SWAP62. We thus replaced the four amino acid residues of Cbln1 (Ser57, Gly58, Ser59, and Ala60) with those of Cbln4 at the corresponding positions to yield SWAP57-60 (Fig. 4G). The W136K substitution mutation of Cbln 1 strongly reduced the interaction with GluR $\delta 2-N T D-F c$, whereas the interaction with NRXN1 $\beta-\mathrm{ECD}-\mathrm{Fc}$ was hardly affected by the mutation (Fig. $4 H, I)$. In contrast, the SWAP57-60 mutation of Cbln 1 reduced the interaction with NRXN1 $\beta$-ECD-Fc, whereas the effect on the interaction with GluR $\delta 2-N T D-F c$ was much smaller. Thus, Trp136 of Cbln 1 is required preferentially for the interaction with GluR $\delta 2$, whereas the amino acid residues 57-60 of Cbln1 are involved mainly for the interaction with NRXN1 $\beta$. A structural model of trimeric $\mathrm{C} 1 \mathrm{q}$ domain of Cbln 1 constructed using collagen trimer as a template suggests that Ser57-Ala60 and Trp136 are located on different surfaces of the C1q domain (Fig. $4 J$ ). These results favor the idea that the binding sites of GluR $\delta 2$ and NRXN $1 \beta$ on Cbln1 are differential rather than identical. Since Cbln1 trimer showed no binding activities to GluR $\delta 2$ and NRXN1 $\beta$ (Uemura et al., 2010), hexamer formation of Cbln1 by dimerization of trimers through a disufide bridge (Bao et al., 2005) is essential for the efficient binding to GluR $\delta 2$ and NRXN1 $\beta$. Interestingly, hexameric Cbln1 may have two symmetric interaction sites for these molecules (Fig. $4 K$ ).

\section{Identification of amino acid residues in $\mathrm{S} 4$ of NRXN1 $\beta$ responsible for Cbln1 binding}

Because Cbln 1 interacts selectively with NRXN variants containing S4 (Uemura et al., 2010; Joo et al., 2011), we examined a series of alanine substitution mutants of respective amino acid residues in S4 of NRXN1 $\beta$ (Gly201 to Lys230) for their binding abilities. We expressed respective mutants tagged with V5 epitope at the $\mathrm{C}$ terminus in HEK293T cells and incubated them with HA-Cbln1. Robust signals for HA-Cbln1 were found on the surface of HEK293T cells transfected with most of NRXN1 $\beta$ mutants, but the signals were strongly diminished for Ala substitution mutants of Arg218 and Trp226 (Fig. 5A,B). These residues important for the interaction with Cbln 1 are located at both sides of the $\beta$-sheet structure in $\mathrm{S} 4$ and are distinct from the NLGN-binding interface of NRXN1 $\beta$ (Koehnke et al., 2010) (Fig. 5C).
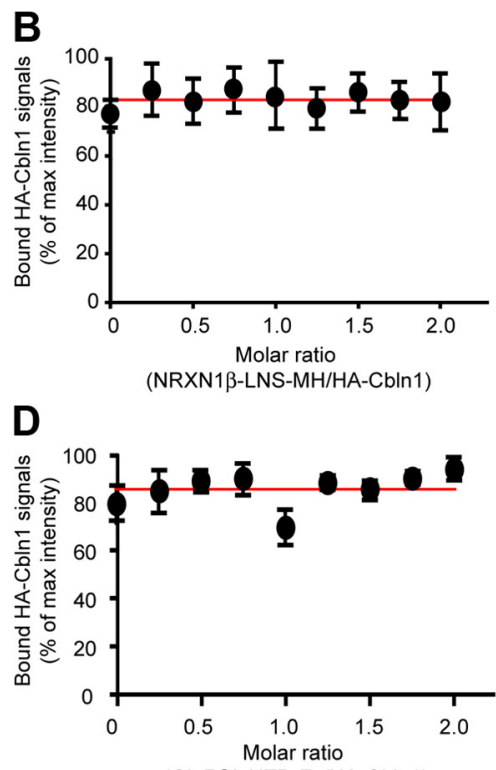

(GluRס2-NTD-Fc/HA-Cbln1)
Figure 6. GluR $\delta 2-N T D$ and NRXN1 $\beta$-LNS are not competitive for binding to Cbln1. $\boldsymbol{A}, \boldsymbol{B}$, Pull-down assay. $\boldsymbol{A}$, Mixtures of 10 pmol of dimeric GluR $\delta 2-N T D-F c, 20$ pmol of hexameric HA-Cbln1, and various amounts $(5,10,15,20,25,30,35$, and 40 pmol) of

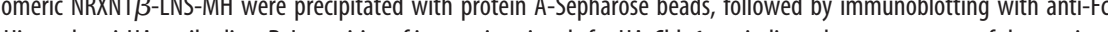
immunoblotting with anti-Fc, anti-His, and anti-HA antibodies. $\boldsymbol{D}$, Intensities of interaction signals for HA-Cbln1 are indicated as
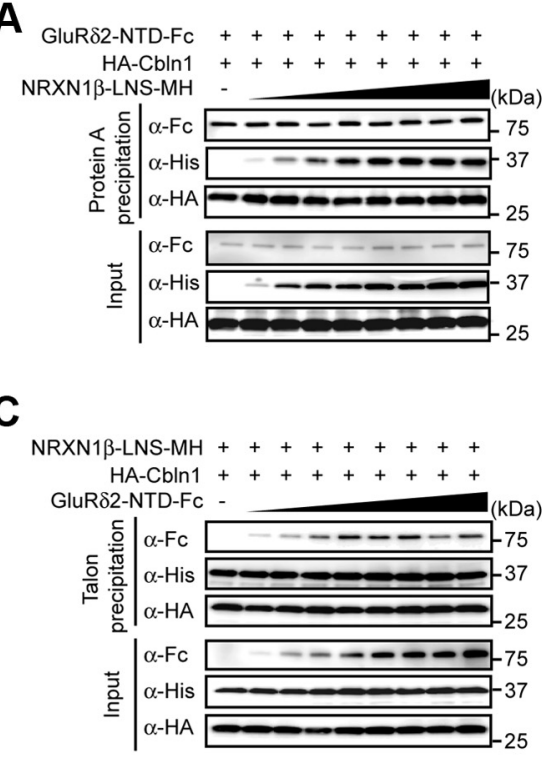

10

\section{No competition between GluR $\delta 2$ and NRXN1 $\beta$ for binding to Cbln1}

Since mutagenesis studies suggest that the binding sites of GluR $\delta 2$ and NRXN1 $\beta$ on Cbln 1 are differential, we then examined whether GluR $\delta 2$ and NRXN1 $\beta$ compete with each other for binding to Cbln 1 or not. Twenty picomoles of hexameric HACbln1 were incubated with 10 pmol of dimeric GluR $\delta 2-N T D-F c$ in the presence of various amounts $(5-40 \mathrm{pmol})$ of monomeric NRXN1 $\beta$-LNS-MH. When the mixture was precipitated with protein A-Sepharose beads, NRXN1 $\beta$-LNS-MH and HA-Cbln 1 were coprecipitated together with GluR $\delta 2-N T D-F c$ (Fig. 6A). The signals of HA-Cbln1 bound to GluR $\delta 2-N T D-F c$ were not significantly altered by the presence of varying amounts of NRXN1 $\beta$-LNS-MH (Fig. 6B). We next incubated 20 pmol each of monomeric NRXN1 $\beta$-LNS-MH and hexameric HA-Cbln 1 in the presence of various amounts $(5-40 \mathrm{pmol})$ of dimeric GluR $\delta 2-N T D-F c$. Talon affinity resins coprecipitated GluR $\delta 2-$ NTD-Fc and HA-Cbln 1 together with NRXN1 $\beta$-LNS-MH (Fig. 6C). The signals of HA-Cbln 1 bound to NRXN1 $\beta$-LNS-MH were not significantly affected by the presence of varying amounts of GluR $\delta 2-N T D-F c$ (Fig. 6D). These results suggest that there is no competition in the binding to Cbln 1 between GluR $\delta 2$ NTD and NRXN1 $\beta$-LNS during triad formation. Thus, it will be possible to understand the assembly stoichiometry of the GluR $\delta 2-C b \ln 1-N R X N 1 \beta$ triad by examining the molar ratio of GluR $\delta 2-C b \ln 1$ interaction and that of Cbln1-NRXN1 $\beta$ interaction one by one.

One molecule of dimeric GluR $\delta 2$-NTD binds to one molecule of hexameric Cbln 1

To examine the stoichiometry of GluR $\delta 2-N T D$ and Cbln1 interaction, we expressed HA-Cbln1-His in HEK293F cells (Fig. 7A), and secreted protein was purified with Talon metal affinity resin. 
A

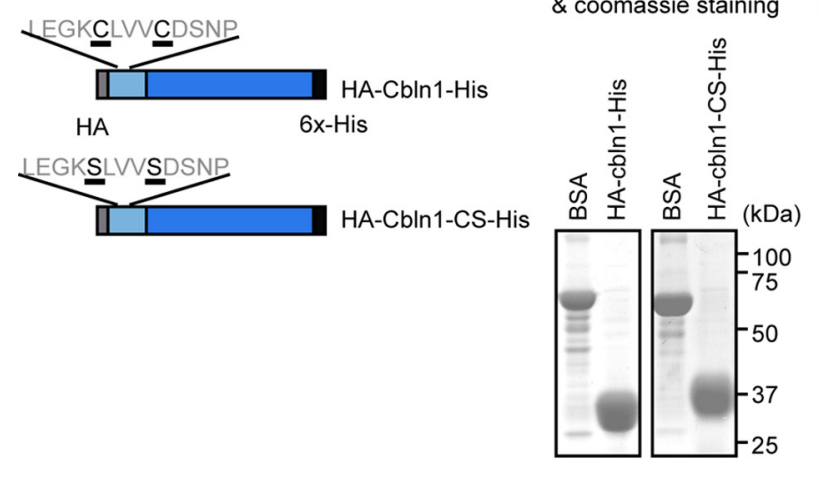

B

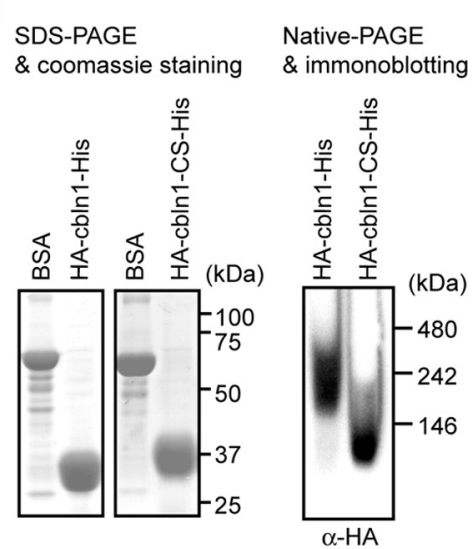

C
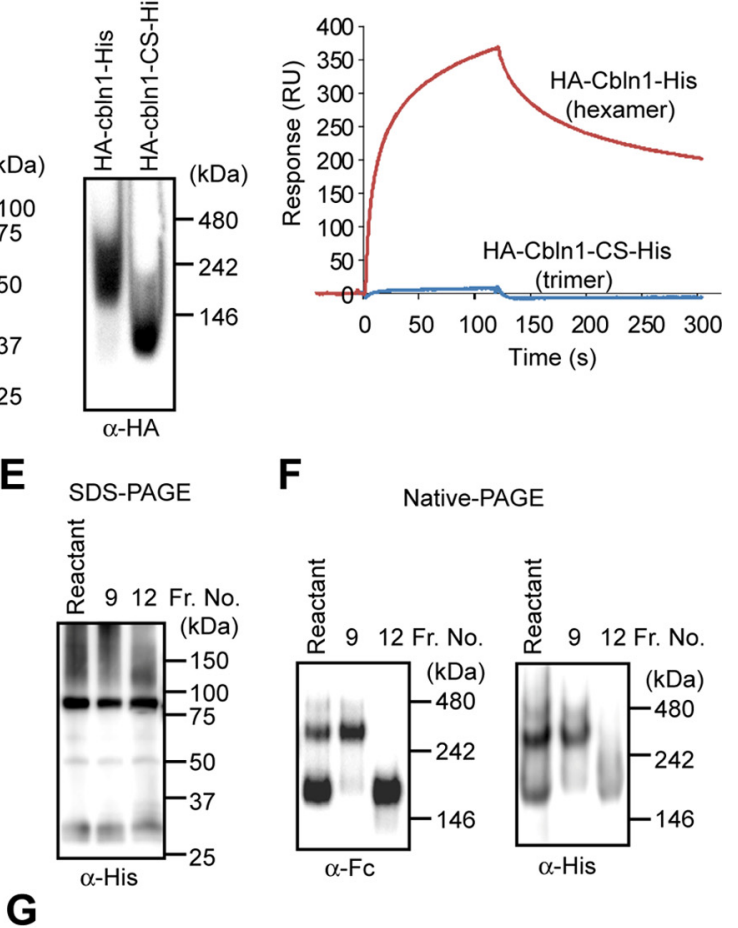

$\mathbf{F}$

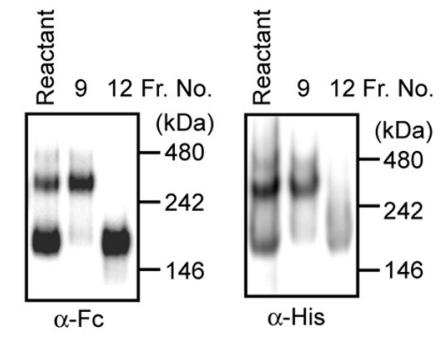

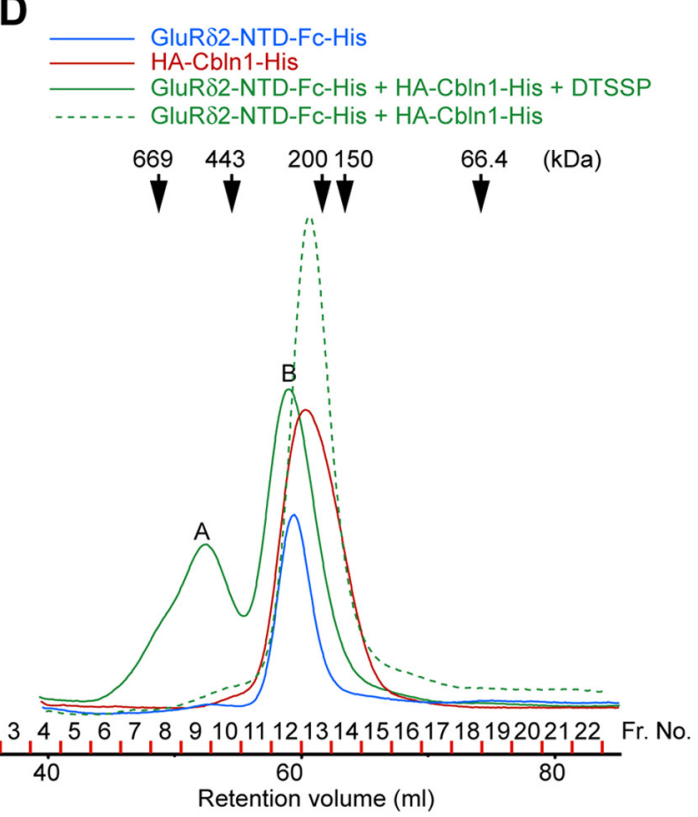

$37^{\circ} \mathrm{C}$

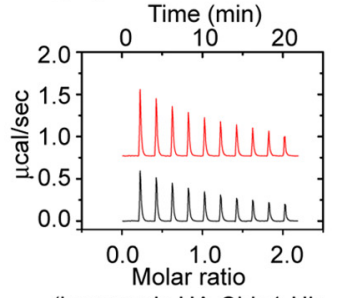

(hexameric HA-Cbln1-His / dimeric GluR82-NTD-Fc-His)

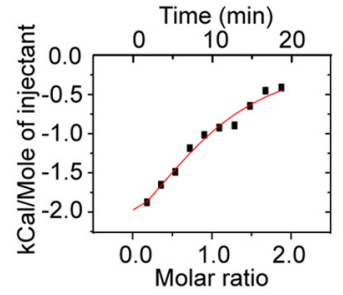

(hexameric HA-Cbln1-His / dimeric GluR82-NTD-Fc-His)

Figure 7. Assembly stoichiometry of GluR $\delta 2-N T D$ and Cbln1 complex. A, Schematic structures of HA-Cbln1-His and HA-Cbln1-CS-His. The amino acid sequence of Cbln1 surrounding cysteine residues 34 and 38 and that of $\mathrm{Cbln} 1-\mathrm{CS}$ are shown. Underlines indicate the cysteine residues of $\mathrm{Cb} \ln 1$ and the corresponding serine residues of Cbln1-CS. B, SDS-PAGE and native-PAGE of purified HA-Cbln1-His and HA-Cbln1-CS-His, followed by Coomassie staining and immunoblotting with anti-HA antibody. C, SPR sensorgrams of $125 \mathrm{~nm}$ HA-Cbln1-His and HA-Cbln1-CS-His over GluRס2-

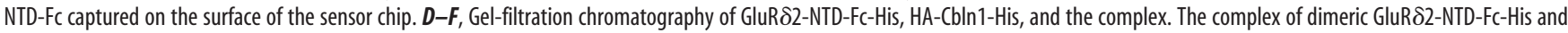
hexameric HA-Cbln1-His (1 nmol each) was stabilized by the treatment with 50 molar excess of cross-linker DTSSP before loading onto the column. $\boldsymbol{D}$, The absorbance at $280 \mathrm{~nm}$ was monitored. $\boldsymbol{E}$, $\boldsymbol{F}$, Fractions 9 and 12 were analyzed by SDS-PAGE followed by immunoblotting with anti-His antibody $(\boldsymbol{E})$ and by native-PAGE followed by immunoblotting with anti-Fc or anti-His antibody $(\boldsymbol{F})$. $\boldsymbol{G}$, Isothermal titration calorimetry assay. A solution of $32.9 \mu \mathrm{m} \mathrm{HA-Cbln1-His} \mathrm{in} \mathrm{the} \mathrm{injection} \mathrm{syringe} \mathrm{was} \mathrm{titrated} \mathrm{into} 200 \mu \mathrm{l}$ of $3.6 \mu \mathrm{m} \mathrm{GluR} \delta 2-\mathrm{NTD}-\mathrm{Fc}-\mathrm{His}$ or the dialysis buffer in the cell at $37^{\circ} \mathrm{C}$. The reaction heat (black) is corrected by subtracting dilution heat (red) of HA-Cbln1-His in the dialysis buffer.

On native-PAGE, HA-Cbln1-His showed a protein band of $\sim 180$ $\mathrm{kDa}$, whereas the size of monomeric HA-Cbln1-His estimated by SDS-PAGE was $\sim 30 \mathrm{kDa}$ and the calculated MW was $21.2 \mathrm{kDa}$ (Fig. 7B). These observations were consistent with the finding of Bao et al. (2005) that Cbln1 forms a trimer through the C-terminal globular C1q domain and subsequently a hexamer through the cysteine residues 34 and 38 at the $\mathrm{N}$ terminus. We also confirmed that HA-Cbln1-CS-His, in which serine residues were substituted for these cysteine residues (Fig. 7A), showed a protein band of $\sim 90 \mathrm{kDa}$ on native-PAGE, which corresponded to the size of trimer (Fig. 7B). When subjected to a SPR binding assay, HA-Cbln1-His but not HA-Cbln1-CS-His interacted well with GluR82-NTD-Fc-His (Fig. 7C).

We then examined the stoichiometry of the interaction between dimeric GluR $\delta 2$-NTD and hexameric Cbln 1 by FPLC gelfiltration analysis. In this assay, the apparent size of hexameric
HA-Cbln1-His estimated using MW standards as references was $\sim 256 \mathrm{kDa}$ (Fig. $7 D)$, being larger than the size $(\sim 180 \mathrm{kDa})$ observed in native-PAGE, as was the case of GluR $\delta 2-\mathrm{NTD}-\mathrm{Fc}-\mathrm{His}$. We incubated purified dimeric GluR $\delta 2-\mathrm{NTD}-\mathrm{Fc}-\mathrm{His}$ and hexameric HA-Cbln1-His in a molar ratio of 1:1 and treated the mixture with cross-linker DTSSP for FPLC to avoid the dissociation of GluR $82-\mathrm{NTD}-\mathrm{Fc}$-His and HA-Cbln1-His complexes during flow in the column (Fig. 7D). Injection of the cross-linked complexes onto a gel-filtration column yielded two major peaks, corresponding to $486 \mathrm{kDa}$ (peak A) and $286 \mathrm{kDa}$ (peak B) (Fig. 7D). SDS-PAGE followed by immunoblotting with anti-His antibody revealed that fractions 9 and 12 corresponding to peaks $\mathrm{A}$ and $\mathrm{B}$, respectively, contained $90 \mathrm{kDa}$ of GluR $\delta 2-\mathrm{NTD}-\mathrm{Fc}$-His and 30 $\mathrm{kDa}$ of HA-Cbln1-His (Fig. 7E). When subjected to native-PAGE followed by immunoblotting with anti-Fc or anti-His antibody, fraction 9 showed a protein band of $\sim 350 \mathrm{kDa}$, corresponding to 
A

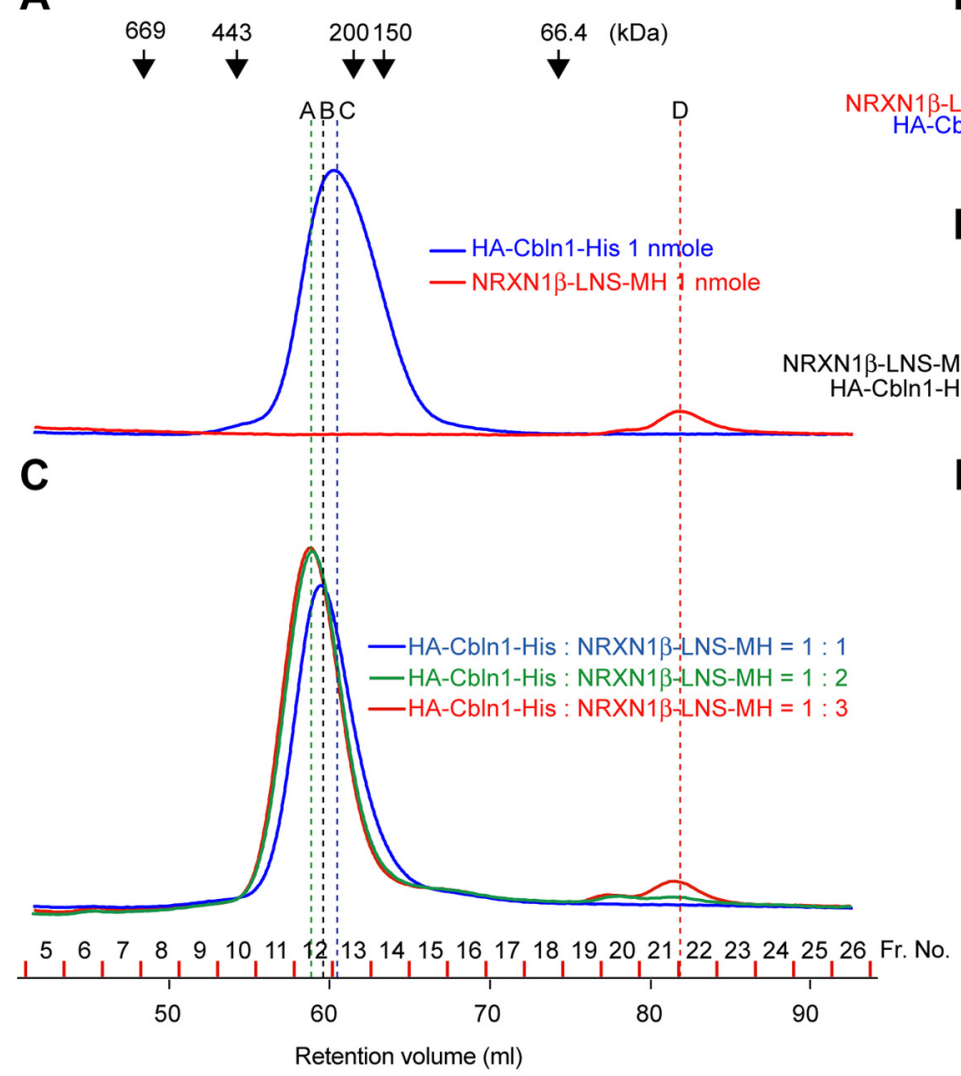

B

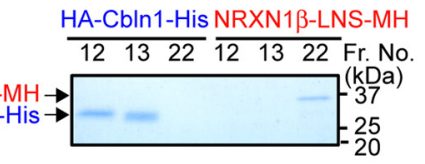

D HA-Cbln1-His : NRXN1及-LNS-MH $\frac{1: 1}{1: 2} \frac{1: 3}{12}$ $\begin{array}{lllllll}12 \quad 13 \quad 22 & 12 \quad 13 \quad 22 & 12 \quad 13 \quad 22 & \text { Fr. No. } \\ (\mathrm{kDa}) & \end{array}$

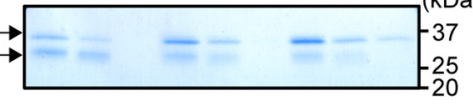

E

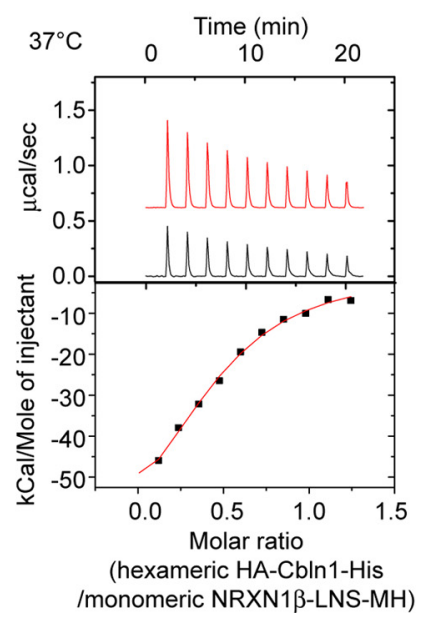

Figure 8. Assembly stoichiometry of NRXN1 $\beta$-LNS and Cbln1 complex. $A, B$, Gel-filtration chromatography of NRXN1 $\beta$-LNS-MH and HA-Cbln1-His. One nanomole of monomeric NRXN1 $\beta$ LNS-MH or hexameric HA-Cbln1-His was loaded onto the column. $\boldsymbol{A}$, The absorbance at $280 \mathrm{~nm}$ was monitored. $\boldsymbol{B}$, Fractions 12,13 , and 22 were analyzed by SDS-PAGE followed by Coomassie staining. $\boldsymbol{C}, \boldsymbol{D}$, Gel-filtration chromatography of mixtures of hexameric HA-Cbln1-His and monomeric NRXN1 $\beta$-LNS-MH. C, Hexameric HA-Cbln1-His and monomeric NRXN1 $\beta$-LNS-MH were mixed in the molar ratios of 1:1, 1:2, and 1:3 and loaded onto the column. The absorbance at $280 \mathrm{~nm}$ was monitored. $\boldsymbol{D}$, Fractions 12,13 , and 22 were analyzed by SDS-PAGE followed by Coomassie staining. $\boldsymbol{E}$, Isothermal titration calorimetry assay. A solution of $32.9 \mu \mathrm{m} \mathrm{HA-Cbln1-His} \mathrm{in} \mathrm{the} \mathrm{injection} \mathrm{syringe} \mathrm{was} \mathrm{titrated} \mathrm{into} 200 \mu \mathrm{l}$ of $5.3 \mu \mathrm{m} \mathrm{NRXN1} \beta$-LNS-MH or the dialysis buffer in the cell at $37^{\circ} \mathrm{C}$. The reaction heat (black) is corrected by subtracting dilution heat (red) of HA-Cbln1-His in the dialysis buffer.

the size of the complex of GluR $\delta 2-\mathrm{NTD}-\mathrm{Fc}-\mathrm{His}$ and HA-Cbln1His, whereas protein bands of $\sim 180 \mathrm{kDa}$ corresponding to the sizes of respective molecules were found in fraction 12 (Fig. $7 F$ ).

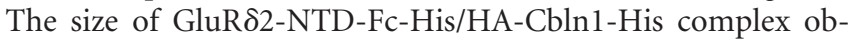
tained by native-PAGE corresponded to the sum of the value of one dimeric GluR 82 -NTD-Fc-His and that of one hexameric HA-Cbln1-His, suggesting that the two molecules interact with each other in a ratio of 1:1.

In an ITC analysis, net changes of thermograms were recorded as a function of $32.9 \mu \mathrm{M}$ HA-Cbln1-His titrated into $3.6 \mu \mathrm{M}$ GluR $\delta 2-\mathrm{NTD}-\mathrm{Fc}-\mathrm{His}$ at $37^{\circ} \mathrm{C}$, which were integrated with respect to time and normalized per mole of hexameric HA-Cbln1-His (Fig. 7G). Fitting of these data with a single binding model yielded a stoichiometry value of $1.1 \pm 0.14$ dimeric GluR $\delta 2-\mathrm{NTD}-\mathrm{Fc}$-His bound per hexameric HA-Cbln1-His. These results also suggest that one molecule of hexameric Cbln1 binds to one molecule of dimeric GluR $\delta 2-N T D$.

\section{One molecule of hexameric Cbln1 interacts with two molecules of NRXN1 $\beta$-LNS}

We next examined the stoichiometry of NRXN1 $1 \beta$-LNS and Cbln1 interaction. On a gel-filtration column, NRXN1 $\beta$ LNS-MH showed a peak of $33.5 \mathrm{kDa}$ (peak D), which corresponded to the size estimated by SDS-PAGE $(35 \mathrm{kDa})$ and calculated MW (30.4 kDa) (Fig. 8A,B). Thus, NRXN1 $\beta$ LNS-MH existed as a monomer. After incubation of NRXN1 $\beta$ -
LNS-MH with hexameric HA-Cbln1-His at the 1:1 molar ratio for $3 \mathrm{~h}$, a peak of $276 \mathrm{kDa}$ (peak B) appeared at the position slightly larger than that of hexameric HA-Cbln1-His (peak C) on the chromatogram, and there was no detectable signal at the position of monomeric NRXN1 $\beta$-LNS-MH (Fig. $8 C$ ). Thus, all NRXN1 $\beta$-LNS-MH appeared to interact with HA-Cbln1-His and showed a mobility shift. When NRXN $1 \beta$-LNS-MH and hexameric HA-Cbln1-His were incubated at the molar ratio of $2: 1$, a peak of $297 \mathrm{kDa}$ (peak A) appeared at the position slightly larger than peak B on the chromatogram. Notably, little signal was observed at the position corresponding to peak $\mathrm{D}$, suggesting that most of NRXN1 $\beta$-LNS-MH appeared to interact with HACbln1-His even under the twofold excess condition. When NRXN1 $\beta$-LNS-MH and hexameric HA-Cbln1-His were incubated at the molar ratio of 3:1, peak A remained unaltered, and a peak corresponding to monomeric NRXN1 $\beta$-LNS-MH appeared. Fractions 12 and 13 corresponding to peaks A-C contained both NRXN1 $\beta$-LNS-MH and HA-Cbln1-His, whereas NRXN1 $\beta$-LNS-MH alone was detected in fraction 22 corresponding to peak $\mathrm{D}$ (Fig. $8 D$ ). These results suggest that one molecule of hexameric HA-Cbln1-His interacts with two molecules of NRXN1 $\beta$-LNS-MH.

We also examined the stoichiometry of NRXN1 $\beta$-LNS and Cbln1 by an ITC analysis. Purified HA-Cbln1-His was titrated into the ITC cell containing NRXN1 $\beta$-LNS-MH. Net changes of thermograms were recorded as a function of $32.9 \mu \mathrm{M} \mathrm{HA}-\mathrm{Cbln} 1-$ 
His titrated into $5.3 \mu \mathrm{M}$ NRXN1 $\beta$-LNS-MH at $37^{\circ} \mathrm{C}$, which were integrated with respect to time and normalized per mole of hexameric HA-Cbln1-His (Fig. $8 E$ ). Fitting of these data with a single binding model yielded a stoichiometry value of $2.2 \pm 0.12 \mathrm{mo}-$ nomeric NRXN1 $\beta$-LNS-MH bound per hexameric HA-Cbln1His. These results suggest that two molecules of monomeric NRXN1 $\beta$-LNS interact with one molecule of hexameric Cbln1. Based on the assembly stoichiometry, the $K_{\mathrm{D} 1}$ value for the first interaction between NRXN1 $\beta$ and Cbln 1 was calculated to be $42.9 \mathrm{~nm}$ by bivalent reaction model using BIAevaluation 4.1 from the data of SPR binding assay (Uemura et al., 2010).

\section{Discussion}

Elucidation of molecular mechanisms that regulate synapse formation in the brain is a prerequisite for the understanding of neural wiring, higher brain functions, and mental disorders. There is clear evidence that postsynaptic GluR $\delta 2$ plays an essential role in vivo in the formation and maintenance of the PF-PC synapse in the cerebellum (Kashiwabuchi et al., 1995; Kurihara et al., 1997; Takeuchi et al., 2005). Recently, we revealed that GluR $\delta 2$ mediates PF-PC synapse formation in vivo by interacting with presynaptic NRXNs through Cbln1 (Uemura et al., 2010). Then, the question arises how the trans-synaptic triad formation induces synapse formation. Here, we determined the assembly stoichiometry of the GluR $\delta 2-\mathrm{Cb} \ln 1-\mathrm{NRXN} 1 \beta$ triad. Based on the stoichiometry of the triad, we suggest that GluR $\delta 2$ triggers synapse formation by clustering four presynaptic NRXNs through triad formation.

\section{Tetrameric GluR $\delta 2$ for synapse formation}

The GluR $\delta$ subtype positions between the AMPA/kainate and NMDA subtypes based on the amino acid sequence identity (Yamazaki et al., 1992; Araki et al., 1993; Lomeli et al., 1993). Cumulative evidence indicates the tetrameric assembly of the AMPA/ kainate- and NMDA-type GluRs (Rosenmund et al., 1998; Laube et al., 1998; Bowie and Lange, 2002; Sun et al., 2002; Weston et al., 2006). We showed that the mobility of GluR $\delta 2$ molecules from the membrane fraction corresponded to the size of the tetramer in BN-PAGE (Fig. 1). The GluR $\delta 2$ band collapsed into monomeric and dimeric intermediates by the treatment of $1 \%$ SDS. These behaviors were similar between GluR $\delta 2$ and AMPA-type GluR. These results suggest that GluR $\delta 2$ exists as a tetramer in the membrane. On the other hand, GluR $\delta 2-\mathrm{NTD}$ assembled into a stable homodimer. The NTD of ionotropic GluRs (iGluRs) with a tetrameric structure assembles as a dimer of dimers (Schorge and Colquhoun, 2003; Tichelaar et al., 2004; Midgett and Madden, 2008; Kumar et al., 2009), and tetrameric iGluRs have twofold symmetry rather than fourfold symmetry (Armstrong and Gouaux, 2000; Sobolevsky et al., 2004, 2009; Nanao et al., 2005).

We previously showed that GluR $\delta 2-N T D$ is required and sufficient for the induction of presynaptic differentiation of cultured cerebellar GCs (Uemura and Mishina, 2008; Uemura et al., 2010). GluR $\delta 2-N T D-F c$ coated on protein A-conjugated beads has an ability to interact with NRXNs in the presence of Cbln1 and to induce presynaptic differentiation (Uemura et al., 2010). When incubated with cultured cerebellar GCs, however, dimeric GluR $\delta 2-N T D$ exerted little effect on the intensities of punctate immunostaining signals for Bassoon and VGluT1. In contrast, tetrameric GluR $\delta 2-\mathrm{NTD}$ prepared by cross-linking dimeric GluR $\delta 2-N T D-F c$ using F $\left(\mathrm{ab}^{\prime}\right)_{2}$ of anti-Fc antibody enhanced the accumulation of the active zone and synaptic vesicle proteins in axons of cultured GCs. These results suggest that native GluR $\delta 2$ is

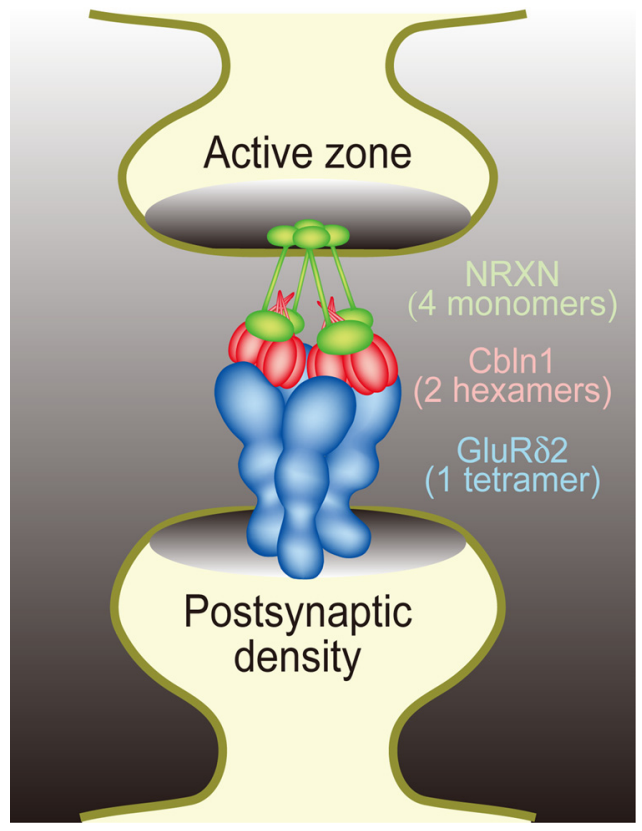

Figure 9. Proposed assembly stoichiometry of GluR $\delta 2-C b \ln 1-N R X N$ triad. One molecule of tetrameric GluR $\delta 2$, two molecules of hexameric Cbln1, and four molecules of monomeric NRXN are assembled to form the trans-synaptic triad that mediates PF-PC synapse formation in the cerebellum. Our results suggest that the interaction sites of Cbln 1 for GluR $\delta 2$ and NRXN $1 \beta$ are differential and hexameric Cbln1 may have two symmetric interaction sites for these molecules. Based on this model, we propose that GluR $\delta 2$ triggers synapse formation by clustering four NRXNs through triad formation.

assembled into a tetramer and this tetrameric assembly is essential for GluR $\delta 2$ to induce presynaptic differentiation.

Assembly stoichiometry of the GluR $\delta 2-C b \ln 1-N R X N 1 \beta$ triad We have proposed a linear trans-synaptic model of the GluR $\delta 2$ Cbln1-NRXN triad as the synaptogenic organizer since Cbln1 is a high-affinity ligand for both GluR $\delta 2$ and NRXN (Uemura et al., 2010). Examinations of the binding affinities of a series of chimeras between Cbln 1 and Cbln 4 and mutant Cbln 1 with substitutions for GluR $\delta 2-N T D$ and NRXN1 $\beta$-ECD suggest that the binding sites of Cbln 1 for GluR $\delta 2$ and NRXN1 $\beta$ are differential rather than identical. In addition, no competition was detectable in the binding to Cbln 1 between GluR $\delta 2-N T D$ and NRXN1 $\beta$-LNS during triad formation. These results suggest that GluR $\delta 2$ and Cbln 1 interact with each other rather independently of Cbln1-NRXN1 $\beta$ interaction and vice versa. We thus examined the assembly stoichiometries of GluR $\delta 2-C b \ln 1$ and Cbln1-NRXN1 $\beta$ complexes one by one.

Both FPLC gel-filtration assay and ITC analysis consistently showed that dimeric GluR $\delta 2-N T D$ and hexameric Cbln 1 assembled in the molar ratio of 1:1, whereas hexameric Cbln 1 and monomeric NRXN1 $\beta$-LNS assembled in the molar ratio of 1:2. Thus, Cbln1 secreted from cerebellar GCs (Bao et al., 2005) should induce the dimer formation of NRXNs through binding. However, Cbln 1 exerted little effect on the accumulation of presynaptic marker proteins in cultured GC axons. Consistently, dimeric GluR $\delta 2-N T D$ that interacts with one molecule of Cbln1 failed to show any enhancing effect on the accumulation of presynaptic markers in GC axons. Since native GluR $\delta 2$ exists as a tetramer in the membrane and the tetramerization is essential for GluR $\delta 2-N T D$ to stimulate the accumulation of Bassoon and VGluT1 in the axons of cultured GCs, we suggest that the synaptogenic triad is composed of one molecule of tetrameric GluR $\delta 2$, 
two molecules of hexameric Cbln1, and four molecules of monomeric NRXN (Fig. 9).

We found that key amino acid residues important for the interaction with GluR $\delta 2$ and NRXN1 $\beta$ are located on the distinct surfaces of the $\mathrm{C} 1 \mathrm{q}$ domain of Cbln 1 (see Fig. $4 J$ ), consistent with the idea that the binding sites of GluR $\delta 2$ and $N R X N 1 \beta$ on Cbln 1 are differential. Interestingly, hexamer formation of Cbln1, which is essential for efficient binding to GluR $\delta 2$ and NRXN $1 \beta$, may yield two symmetric interaction sites for these molecules (Fig. $4 K$ ), consistent with the assembly stoichiometry of GluR $\delta 2$ Cbln1-NRXN triad.

\section{Mechanism of induction by GluR $\delta 2$ of PF-PC synapse formation}

During development, axons of immature neurons show a capacity for evoked recycling of synaptic vesicles and clusters of the vesicles along axonal segments, even in the absence of target cells (Ziv and Garner, 2004; Jin and Garner, 2008). However, the synaptic vesicle aggregation, in the absence of a postsynaptic contact, is not stably anchored to a given region of the cell surface. Contacts with postsynaptic sites trigger the stabilization and maturation of synapses. In cultured cerebellar GCs, the majority of varicosities containing presynaptic proteins are not apposed to definite postsynaptic structures (Marxen et al., 1999; Urakubo et al., 2003). Cbln1 is a high-affinity ligand for NRXNs (Uemura et al., 2010; Joo et al., 2011) and is secreted from cerebellar GCs (Bao et al., 2005), suggesting that the interaction between secreted Cbln 1 and presynaptic NRXNs takes place before PF-PC synapse formation. However, punctate staining signals for Bassoon were comparable between GC cultures from wild-type and Cbln1 knock-out mice. The addition of Cbln1 to GC cultures exerted little effect on the intensity of Bassoon signals. Thus, the formation of NRXN dimers is not sufficient to induce presynaptic differentiation. Consistently, GluR $\delta 2$-NTD dimer that binds to one molecule of Cbln 1 failed to show any activity to induce presynaptic differentiation. In contrast, GluR $\delta 2$-NTD tetramer stimulated the accumulation of punctate signals for active zone protein Bassoon and synaptic vesicle protein VGluT1 in cultured cerebellar GCs. Since GluR $\delta 2$-NTD tetramer is soluble, it is unlikely that this stimulating effect is attributable to anchoring presynaptic proteins. Our results suggest that tetrameric GluR $\delta 2-N T D$ assembles two molecules of Cbln1 and four molecules of NRXNs, whereas dimeric GluR $\delta 2$-NTD interacts with one molecule of Cbln1 and two molecules of NRXNs. Thus, clustering of four NRXNs by tetrameric GluR $\delta 2-N T D$ via two Cbln 1 seems to be a key step to trigger presynaptic differentiation. Interestingly, with this respect, Dean et al. (2003) showed that anti-VSV antibodies multimerized by secondary antibodies induced clustering of VSV-NRXN $1 \beta$ overexpressed in cultured hippocampal neurons and accumulation of synaptic vesicle proteins, although neither the physiological relevant of this observation nor the exact stoichiometry of the complex was settled.

Based on the assembly stoichiometry of the triad, one molecule of tetrameric GluR $\delta 2$ recruits four molecules of NRXN1 $\beta$ through Cbln1, whereas one molecule of dimeric GluR $\delta 2-N T D$ interacts with two molecules of NRXN1 $\beta$. Thus, we suggest that GluR $\delta 2$ triggers the formation of the PF-PC synapse in the cerebellum not only by stably anchoring presynaptic NRXNs but also by clustering four NRXNs through triad formation. Tetrameric assembly of NRXNs by the interaction with GluR $\delta 2$-Cbln 1 complex is essential for synapse formation, whereas dimeric assembly of NRXNs by the interaction with NLGN dimers is important for synapse maturation (Südhof, 2008). Interestingly, the locations of the amino acid residues in $S 4$ of NRXN1 $\beta$ required for the interaction with Cbln1 are different from the NLGN-binding interface (Fig. 5C). Dimeric or tetrameric assembly and configurations of NRXNs may be important for signaling of synapse formation and maturation. NRXNs interact with synaptotagmin, CASK, Mint, and syntenin through its C terminal (Hata et al., 1993, 1996; Biederer and Südhof, 2000; Grootjans et al., 2000), and the C terminal of NRXN is critical for the induction of presynaptic differentiation in vitro (Dean et al., 2003). Because the interacting complex of CASK and Mint has multivalent binding sites against NRXNs (Butz et al., 1998), tetramerization of NRXNs may stimulate the clustering of these scaffold proteins, leading to the organization of transmitter release machineries (Butz et al., 1998; Maximov et al., 1999; Biederer and Südhof, 2000, 2001). Since CASK phosphorylates NRXNs (Mukherjee et al., 2008), it is also possible that the clustering of NRXNs triggers intracellular signals for presynaptic differentiation. In conclusion, our results suggest that GluR $\delta 2$ triggers PF-PC synapse formation by clustering four NRXNs through the assembly of the trans-synaptic triad.

\section{References}

Andrews P (1964) Estimation of the molecular weights of proteins by Sephadex gel-filtration. Biochem J 91:222-233.

Araki K, Meguro H, Kushiya E, Takayama C, Inoue Y, Mishina M (1993) Selective expression of the glutamate receptor channel $\delta 2$ subunit in cerebellar Purkinje cells. Biochem Biophys Res Commun 197:1267-1276.

Armstrong N, Gouaux E (2000) Mechanisms for activation and antagonism of an AMPA-sensitive glutamate receptor: crystal structure of the GluR2 ligand binding core. Neuron 28:165-181.

Arnold K, Bordoli L, Kopp J, Schwede T (2006) The SWISS-MODEL workspace: a web-based environment for protein structure homology modelling. Bioinformatics 22:195-201.

Bao D, Pang Z, Morgan JI (2005) The structure and proteolytic processing of Cbln1 complexes. J Neurochem 95:618-629.

Biederer T, Südhof TC (2000) Mints as adaptors: direct binding to neurexins and recruitment of Munc18. J Biol Chem 275:39803-39806.

Biederer T, Südhof TC (2001) CASK and protein 4.1 support F-actin nucleation on neurexins. J Biol Chem 276:47869-47876.

Bogin O, Kvansakul M, Rom E, Singer J, Yayon A, Hohenester E (2002) Insight into Schmid metaphyseal chondrocysplasia from the crystal structure of the collagen X NC1 domain trimer. Structure 10:165-173.

Bowie D, Lange GD (2002) Functional stoichiometry of glutamate receptor desensitization. J Neurosci 22:3392-3403.

Butz S, Okamoto M, Südhof TC (1998) A tripartite protein complex with the potential to couple synaptic vesicle exocytosis to cell adhesion in brain. Cell 94:773-782.

Dalva MB, McClelland AC, Kayser MS (2007) Cell adhesion molecules: signalling functions at the synapse. Nat Rev Neurosci 8:206-220.

Dean C, Scholl FG, Choih J, DeMaria S, Berger J, Isacoff E, Scheiffele P (2003) Neurexin mediates the assembly of presynaptic terminals. Nat Neurosci 6:708-716.

Graf ER, Zhang X, Jin SX, Linhoff MW, Craig AM (2004) Neurexins induce differentiation of GABA and glutamate postsynaptic specializations via neuroligins. Cell 119:1013-1026.

Grootjans JJ, Reekmans G, Ceulemans H, David G (2000) SynteninSyndecan binding requires Syndecan-Synteny and the co-operation of both PDZ domains of Syntenin. J Biol Chem 275:19933-19941.

Guex N, Peitsch MC (1997) SWISS-MODEL and the Swiss-PdbViewer: an environment for comparative protein modeling. Electrophoresis 18:2714-2723.

Hata Y, Davletov B, Petrenko AG, Jahn R, Südhof TC (1993) Interaction of synaptotagmin with the cytoplasmic domains of neurexins. Neuron 10:307-315

Hata Y, Butz S, Südhof TC (1996) CASK: a novel dlg/PSD95 homolog with an $\mathrm{N}$-terminal calmodulin-dependent protein kinase domain identified by interaction with neurexins. J Neurosci 16:2488-2494.

Jin Y, Garner CC (2008) Molecular mechanisms of presynaptic differentiation. Annu Rev Cell Dev Biol 24:237-262. 
Joo J-Y, Lee S-J, Uemura T, Yoshida T, Yasumura M, Watanabe M, Mishina M (2011) Differential interactions of cerebellin precursor protein (Cbln) subtypes and neurexin variants for synapse formation of cortical neurons. Biochem Biophys Res Commun 406:627-632.

Kashiwabuchi N, Ikeda K, Araki K, Hirano T, Shibuki K, Takayama C, Inoue Y, Kutsuwada T, Yagi T, Kang Y, Aizawa S, Mishina M (1995) Impairment of motor coordination, Purkinje cell synapse formation, and cerebellar long-term depression in GluR $\delta 2$ mutant mice. Cell 81:245-252.

Koehnke J, Katsamba PS, Ahlsen G, Bahna F, Vendome J, Honig B, Shapiro L, Jin X (2010) Splice form dependence of $\beta$-neurexin/neuroligin binding interactions. Neuron 67:61-74.

Kumar J, Schuck P, Jin R, Mayer ML (2009) The N-terminal domain of GluR6-subtype glutamate receptor ion channels. Nat Struct Mol Biol $16: 631-638$

Kurihara H, Hashimoto K, Kano M, Takayama C, Sakimura K, Mishina M, Inoue Y, Watanabe M (1997) Impaired parallel fiber-Purkinje cell synapse stabilization during cerebellar development of mutant mice lacking the glutamate receptor $\delta 2$ subunit. J Neurosci 17:9613-9623.

Landsend AS, Amiry-Moghaddam M, Matsubara A, Bergersen L, Usami S, Wenthold RJ, Ottersen OP (1997) Differential localization of $\delta$ glutamate receptors in the rat cerebellum: coexpression with AMPA receptors in parallel fiber-spine synapses and absence from climbing fiber-spine synapses. J Neurosci 17:834-842.

Laube B, Kuhse J, Betz H (1998) Evidence for a tetrameric structure of recombinant NMDA receptors. J Neurosci 18:2954-2961.

Lomeli H, Sprengel R, Laurie DJ, Köhr G, Herb A, Seeburg PH, Wisden W (1993) The rat delta- 1 and delta-2 subunits extend the excitatory amino acid receptor family. FEBS Lett 315:318-322.

Losi G, Prybylowski K, Fu Z, Luo JH, Vicini S (2002) Silent synapses in developing cerebellar granule neurons. J Neurophysiol 87:1263-1270.

Lu C, Fu Z, Karavanov I, Yasuda RP, Wolfe BB, Buonanno A, Vicini S (2006) NMDA receptor subtypes at autaptic synapses of cerebellar granule neurons. J Neurophysiol 96:2282-2294.

Marxen M, Volknandt W, Zimmermann H (1999) Endocytic vacuoles formed following a short pulse of $\mathrm{K}^{+}$-stimulation contain a plethora of presynaptic membrane proteins. Neuroscience 94:985-996.

Matsuda I, Mishina M (2000) Identification of a juxtamembrane segment of the glutamate receptor $\delta 2$ subunit required for the plasma membrane localization. Biochem Biophys Res Commun 275:565-571.

Maximov A, Südhof TC, Bezprozvannv I (1999) Association of neuronal calcium channels with modular adaptor proteins. J Biol Chem 274:24453-24456.

McAllister AK (2007) Dynamic aspects of CNS synapse formation. Annu Rev Neurosci 30:425-450.

Midgett CR, Madden DR (2008) The quaternary structure of a calciumpermeable AMPA receptor: conservation of shape and symmetry across functionally distinct subunit assemblies. J Mol Biol 382:578-584.

Missler M, Südhof TC (1998) Neurexins: three genes and 1001 products. Trends Genet 14:20-26.

Miyazaki T, Fukaya M, Shimizu H, Watanabe M (2003) Subtype switching of vesicular glutamate transporters at parallel fibre-Purkinje cell synapses in developing mouse cerebellum. Eur J Neurosci 17:2563-2572.

Mukherjee K, Sharma M, Urlaub H, Bourenkov GP, Jahn R, Südhof TC, Wahl MC (2008) CASK functions as a $\mathrm{Mg}^{2+}$-independent kinase. Cell 133:328-339.

Nanao MH, Green T, Stern-Bach Y, Heinemann SF, Choe S (2005) Structure of the kainite receptor subunit GluR6 agonist-binding domain complexed with domoic acid. Proc Natl Acad Sci U S A 102:1708-1713.

Penn AC, Williams SR, Greger IH (2008) Gating motions underlie AMPA receptor secretion from the endoplasmic reticulum. EMBO J 27:3056-3068.

Rosenmund C, Stern-Bach Y, Stevens CF (1998) The tetrameric structure of a glutamate receptor channel. Science 280:1596-1599.
Scheiffele P, Fan J, Choih J, Fetter R, Serafini T (2000) Neuroligin expressed in nonneuronal cells triggers presynaptic development in contacting axons. Cell 101:657-669.

Schorge S, Colquhoun D (2003) Studies of NMDA receptor function and stoichiometry with truncated and tandem subunits. J Neurosci 23:1151-1158.

Shen K, Scheiffele P (2010) Genetics and cell biology of building specific synaptic connectivity. Annu Rev Neurosci 33:473-507.

Siddiqui TJ, Craig AM (2011) Synaptic organizing complexes. Curr Opin Neurobiol 21:132-143.

Sobolevsky AI, Yelshansky MV, Wollmuth LP (2004) The outer pore of the glutamate receptor channel has 2 -fold rotational symmetry. Neuron 41:367-378.

Sobolevsky AI, Rosconi MP, Gouaux E (2009) X-ray structure, symmetry and mechanism of an AMPA-subtype glutamate receptor. Nature $462: 745-756$

Südhof TC (2008) Neuroligins and neurexins link synaptic function to cognitive disease. Nature 455:903-911.

Sun Y, Olson R, Horning M, Armstrong N, Mayer M, Gouaux E (2002) Mechanism of glutamate receptor desensitization. Nature 417:245-253.

Takayama C, Nakagawa S, Watanabe M, Mishina M, Inoue Y (1996) Developmental changes in expression and distribution of the glutamate receptor channel $\delta 2$ subunit according to the Purkinje cell maturation. Brain Res Dev Brain Res 92:147-155.

Takeuchi T, Miyazaki T, Watanabe M, Mori H, Sakimura K, Mishina M (2005) Control of synaptic connection by glutamate receptor $\delta 2$ in the adult cerebellum. J Neurosci 25:2146-2156.

Tichelaar W, Safferling M, Keinänen K, Stark H, Madden DR (2004) The three-dimensional structure of an ionotropic glutamate receptor reveals a dimer-of-dimers assembly. J Mol Biol 344:435-442.

Uemura T, Mishina M (2008) The amino-terminal domain of glutamate receptor $\delta 2$ triggers presynaptic differentiation. Biochem Biophys Res Commun 377:1315-1319.

Uemura T, Mori H, Mishina M (2004) Direct interaction of GluR $\delta 2$ with Shank scaffold proteins in cerebellar Purkinje cells. Mol Cell Neurosci 26:330-341.

Uemura T, Lee S-J, Yasumura M, Takeuchi T, Yoshida T, Ra M, Taguchi R, Sakimura K, Mishina M (2010) Trans-synaptic interaction of GluR $\delta 2$ and neurexin through Cbln1 mediates synapse formation in the cerebellum. Cell 141:1068-1079.

Urakubo T, Tominaga-Yoshino K, Ogura A (2003) Non-synaptic exocytosis enhanced in rat cerebellar granule neurons cultured under survivalpromoting conditions. Neurosci Res 45:429-436.

Ushkaryov YA, Petrenko AG, Geppert M, Südhof TC (1992) Neurexins: synaptic cell surface proteins related to the alpha-latrotoxin receptor and laminin. Science 257:50-56.

Varoqueaux F, Aramuni G, Rawson RL, Mohrmann R, Missler M, Gottmann K, Zhang W, Südhof TC, Brose N (2006) Neuroligins determine synapse maturation and function. Neuron 51:741-754.

Waites CL, Craig AM, Garner CC (2005) Mechanisms of vertebrate synaptogenesis. Annu Rev Neurosci 28:251-274.

Weston MC, Schuck P, Ghosal A, Rosenmund C, Mayer ML (2006) Conformational restriction blocks glutamate receptor desensitization. Nat Struct Mol Biol 13:1120-1127.

Williams ME, de Wit J, Ghosh A (2010) Molecular mechanisms of synaptic specificity in developing neural circuits. Neuron 68:9-18.

Yamazaki M, Araki K, Shibata A, Mishina M (1992) Molecular cloning of a cDNA encoding a novel member of the mouse glutamate receptor channel family. Biochem Biophys Res Commun 183:886-892.

Ziv NE, Garner CC (2004) Cellular and molecular mechanisms of presynaptic assembly. Nat Rev Neurosci 5:385-399. 